\title{
A novel model for data-driven smart sustainable cities of the future: the institutional transformations required for balancing and advancing the three goals of sustainability
}

Simon Elias Bibri ${ }^{1,2}$

\author{
Correspondence: simoe@ntnu.no \\ ${ }^{1}$ Department of Computer Science, \\ The Norwegian University of \\ Science and Technology, Sem \\ Saelands veie 9, NO 7491 \\ Trondheim, Norway \\ ${ }^{2}$ Department of Architecture and \\ Planning, The Norwegian University \\ of Science and Technology, Alfred \\ Getz vei 3, Sentralbygg 1, 5th floor, \\ NO 7491 Trondheim, Norway
}

\begin{abstract}
In recent years, it has become increasingly feasible to achieve important improvements of sustainability by integrating sustainable urbanism with smart urbanism thanks to the proven role and synergic potential of data-driven technologies. Indeed, the processes and practices of both of these approaches to urban planning and development are becoming highly responsive to a form of datadriven urbanism, giving rise to a new phenomenon known as "data-driven smart sustainable urbanism." Underlying this emerging approach is the idea of combining and integrating the strengths of sustainable cities and smart cities and harnessing the synergies of their strategies and solutions in ways that enable sustainable cities to optimize, enhance, and maintain their performance on the basis of the innovative data-driven technologies offered by smart cities. These strengths and synergies can be clearly demonstrated by combining the advantages of sustainable urbanism and smart urbanism. To enable such combination, major institutional transformations are required in terms of enhanced and new practices and competences. Based on case study research, this paper identifies, distills, and enumerates the key benefits, potentials, and opportunities of sustainable cities and smart cities with respect to the three dimensions of sustainability, as well as the key institutional transformations needed to support the balancing of these dimensions and to enable the introduction of data-driven technology and the adoption of applied data-driven solutions in city operational management and development planning. This paper is an integral part of a futures study that aims to analyze, investigate, and develop a novel model for data-driven smart sustainable cities of the future. I argue that the emerging data-driven technologies for sustainability as innovative niches are reconfiguring the socio-technical landscape of institutions, as well as providing insights to policymakers into pathways for strengthening existing institutionalized practices and competences and developing and establishing new ones. This is necessary for balancing and advancing the goals of sustainability and thus achieving a desirable future.

(Continued on next page)
\end{abstract}


(Continued from previous page)

Keywords: Sustainable cities, Smart cities, Data-driven smart sustainable cities, Ecocities, Compact cities, Institutional transformations, Sustainability dimensions, Datadriven solutions, Operational management, Development planning

\section{Introduction}

Cities are a mark of human civilisation and play a central role in the pursuit of new paradigms of thinking to bring about major transformations to the way people live and change the world in the process. Sustainability has, over the last four decades, been one of the most influential paradigms of thinking within urban development. Cities holding unparalleled potential to address and overcome the challenges of sustainable development largely depends on how they can be planned, designed, and managed, as well as on the extent to which they respond to new global trends and benefit from scientific discoveries and related technological advances. Appropriately redesigning and restructuring urban environments as sustainable cities and adopting innovative solutions to enhance and harness their strategies is a continuous endeavor towards achieving the long-term of goals sustainability.

Compact cities and eco-cities are the central paradigms of sustainable urbanism and the most prevalent and advocated models of sustainable cities. Numerous recent national and international policy reports and papers state that these two models contribute, though to varying degrees, to resource efficiency and reliability, environmental protection, socio-economic development, social cohesion and inclusion, quality of life and well-being, and cultural enhancement (Bibri 2020a). It is argued that the compact city model is able to contribute to and support the balancing of the three dimensions of sustainability (e.g., Bibri et al. 2020; Burton 2002; Jenks and Dempsey 2005; Hofstad 2012; Jenks and Jones 2010; OECD 2012), and that the eco-city model is able to achieve the goals of environmental sustainability and to produce some economic and social benefits of sustainability (Bibri and Krogstie 2020a; Joss 2010; Joss et al. 2013; Kenworthy 2006; Mostafavi and Doherty 2010; Rapoport and Vernay 2011; Suzuki et al. 2010). The change is still inspiring and the endeavor continues to induce scholars, practitioners, and policymakers alike to enhance the existing models of sustainable cities or to propose new integrated models to improve sustainability in today's world of advanced science and technology and intensive urban growth.

Transformative processes within sustainable cities have been in focus for some time now. The motivation for achieving the United Nations' Sustainable Development Goal (SGD) 11 has increased the need to understand, plan, and manage sustainable cities in new and innovative ways (United Nations 2015a). This is in response to the negative unintended consequences of urbanization. Nonetheless, this global trend creates enormous environmental, social, economic, and spatial changes, which provide an opportunity for sustainability with the potential to apply advanced technologies in order to use resources more efficiently and control them more safely, to promote more sustainable land use, and to preserve the biodiversity of natural ecosystems and reduce pressure on their services, with the ultimate aim to improve economic and societal outcomes. The United Nations's 2030 Agenda regards advanced Information and Communication Technology (ICT) as a means to promote socio-economic development 
and protect the environment, increase resource efficiency, achieve human progress and knowledge in societies, upgrade legacy infrastructure, and retrofit industries based on sustainable design principles (United Nations 2015b). This relates to the multifaceted potential of smart cities, which has been under study with respect to the role of big data technologies and their novel applications in strategic sustainable development within the framework of 2030 Agenda (United Nations 2015c). The abundance of data opens up for new opportunities for innovation in sustainable cities.

Big data technologies are heralding a new era wherein sustainable cities are morphing in response to the influence brought by the emerging paradigm of big data computing. Indeed, there has recently been a conscious push for sustainable cities across the globe to be smarter and thus more sustainable by adopting data-driven technologies to enhance and optimize their operations, functions, services, designs, strategies, and policies. This transformation-which entails new and innovative ways of how sustainable cities can be monitored, understood, analyzed, and thus planned, organized, controlled, and regulated-is manifest in the increasingly level of the development and implementation of data-driven solutions in their operational management mechanisms and development planning approaches. In fact, big data technologies have, in the context of sustainability, become as essential to the functioning of smart cities (e.g., Angelidou et al. 2017; Bibri 2019a; Bibri and Krogstie 2020b, c; Bettencourt 2014; Eden Strategy Institute 2018; Hashem et al. 2016; Kumar and Prakash 2016; Nikitin et al. 2016; Perera et al. 2017; Thakuriah et al. 2017) as to that of sustainable cities (e.g., Bibri 2020b, c; Bibri and Krogstie 2017, 2020a c; Pasichnyi et al. 2019; Shahrokni et al. 2014a, b; Shahrokni et al. 2015a, b; Sun and Du 2017; Thornbush and Golubchikov 2019). It is worth pointing out that while sustainable cities has had the leading position in tackling the challenges of sustainable development since the early 1990s, it was not until recently that smart cities gained momentum for facilitating the transition towards sustainable development thanks to the Internet of Things (IoT) and big data analytics. Regardless, urban processes and practices are becoming highly responsive to a form of data-driven urbanism. In other words, we are moving into an era where instrumentation, datafication, and computation are routinely pervading the very fabric of both sustainable cities and smart cities. One of the consequences of data-driven smart sustainable urbanism is that city systems and domains are becoming much more tightly interlinked, integrated, and coordinated. And also, vast troves of data are being generated, analyzed, harnessed, and exploited to make sustainable cities safer, cleaner, more resilience, and, above all, more efficient.

There are many opportunities yet to explore for integrating sustainable cities and smart cities in terms of their operational management and development planning in order to overcome or mitigate the extreme fragmentation of their landscapes and the weak connection of their strategies and solutions (e.g., Ahvenniemi et al. 2017; Angelidou et al. 2017; Bibri 2019b, 2020; Bifulco et al. 2016) under what is labelled "datadriven smart sustainable cities." Underlying this emeging paradigm of urbanism is the idea of combining the strengths of sustainable cities and smart cities and harnessing the synergies of their strategies and solutions in ways that first and foremost enhance, optimize, and maintain the performance of sustainable cities on the basis of the innovative data-driven technologies offered by smart cities. These strengths and synergies can be clearly demonstrated by combining the advantages of sustainable urbanism and 
smart urbanism. To enable such combination, major institutional transformations are required in terms of enhanced and new practices and competences.

As a process of change, data-driven smart sustainable cities as an emerging approach to sustainable urban development is where "the direction of investments, the orientation of technological development, and institutional changes are all in harmony and enhance both current and future potential to meet human needs and aspirations" (World Commission on Environment and Development (WCED) 1987). Drastic shifts to socio-technological regimes-transforming technological regimes for sustainable urban development-"entail concomitantly radical changes to the socio-technical landscape of politics, institutions, the economy, and social values" (Smith 2003, p. 131). Sociotechnological regimes-i.e., "interconnected systems of artifacts, institutions, rules, and norms" (Berkhout etal. 2003, p. 3) - are to be brought about by the actions and networks of existing actors within civic institutions in the ambit of emerging data-driven smart sustainable cities. As stated by Bibri and Krogstie (2016, p. 33), "established socio-technological regimes can induce and support the transformation of socio-technical constellations (e.g., industry associations, research communities, policy networks, and advocacy/special-interest groups) towards improving and advancing sustainability at the macro level."

Data-driven technologies and data-oriented institutions are benefiting from the provisioning of innovative applications and enhanced decision-making processes in response to the need for solving or mitigating the challenges of sustainability and urbanization. This in turn implies that they are displaying positive feedbacks through the increasing implementation of applied solutions and policy instruments, respectively, in sustainable cities and smart cities such that the more they are implemented, the more likely they are to be further implemented. Social processes behind this phenomenon commonly include network effects, interactive processes, adaptation, coordination, and learning.

This paper identifies, distills, and enumerates the key benefits, potentials, and opportunities of sustainable cities and smart cities with respect to the three dimensions of sustainability, as well as the key institutional transformations needed to support the balancing of these dimensions and to enable the introduction of datadriven technology and the adoption of applied data-driven solutions in city operational management and development planning.

This paper is based on the four case studies conducted as part of prior work on:

- compact cities (Bibri et al. 2020);

- eco-cities (Bibri and Krogstie 2020a);

- data-driven smart cities (Bibri and Krogstie 2020b); and

- environmentally data-driven smart sustainable cities (Bibri and Krogstie 2020c).

This is part of an extensive futures study, which aims to analyse, investigate, and develop a novel model for data-driven smart sustainable cities of the future. This takes the form of a strategic planning process of transformative change towards sustainability (Bibri and Krogstie 2021).

The futures study consists of 6 Steps in total, each with several guiding questions to answer. The answer to the guiding questions for each of these steps may involve one, two, or more 
papers, and one paper may in turn answer the guiding questions for one or two steps. This paper answers the last guiding question for both Step 5 and Step 6. Combining the answer to these two question in one paper is motivated by their interrelationship in regard to the three goals of sustainability, and the role of data-based city management in improving the contribution to these goals. The two guiding questions for Step 5 and Step 6 are as follows:

1. What are the key benefits, potentials, and opportunities of the future vision model of urbanism?

2. What institutional changes are necessary for attaining the future vision?

This paper unfolds as follows: Section 2 presents the methodological framework for the futures study. Section 3 presents the results. Section 5 discusses the results. This paper ends, in Section 5, with concluding remarks.

\section{Research methodology}

The methodological framework applied in the futures study combines and integrates normative backcasting and descriptive case study as qualitative approaches. The backcasting approach was employed to achieve the overall aim of the futures study. The case study approach, which is associated with the empirical phase of the futures study, was adopted to examine and compare two of a total of six cases from the ecologically and technologically leading cities in Europe with respect to each of the phenomena of compact cities, eco-cities, data-driven smart cities, and environmentally data-driven smart sustainable cities. Bibri (2020) dedicates a whole article to the methodological framework for strategic data-driven smart sustainable city planning whose core objective is clarifying which city model is desired and working towards that specified outcome. Table 1 presents the guiding questions for each of the six steps in the backcasting study, and highlights the two questions addressed by this paper in Step 5 and Step 6.

\section{Backcasting as a strategic planning process}

The term "backcasting," which was coined by Robinson in 1982, can denote a concept, a study, an approach, a methodology, a framework, or an interactive process among stakeholders. Hence, it has been defined in multiple ways. Robinson (1990, p. 823) defines backcasting as a normative approach that works "backwards from a particular desired end point to the present in order to determine the feasibility of that future and what policy measures would be required to reach that point." Once the future desired conditions are imagined and articulated, the necessary steps are defined and pursued to attain those conditions (Fig. 1). In recent years, backcasting has been mostly applied in the futures studies that deal with long-term problems and sustainability solutions (see, e.g., Akerman 2005; Akerman and Höjer 2006; Höjer et al. 2011; Miola 2008; Quist et al. 2001; Quist 2007; Vergragt and Quist 2011; Wangel 2011). However, the backcasting process in this futures study represents a strategic planning framework for facilitating progress towards achieving the goals of sustainability for those cities that are badging or regenerating themselves as sustainable, or manifestly planning to become 
Table 1 The guiding questions for each step in the backcasting-oriented futures study

The guiding questions for the backcasting study

Step 1: Detail strategic problem orientation (Part 1)

1. What is the model of urbanism to be studied?

2. What are the aim, purpose, and objectives of the backcasting study in relation to this model?

3. What are the long-term targets declared by the goal-oriented backcasting approach?

4. What are the objectives these targets are translated to for backcasting analysis?

\section{Step 2: Detail strategic problem orientation (Part 2)}

1. What are the main prevailing trends and expected developments related to the model to be studied?

2. What are the key sustainability problems associated with the current model of urbanism and what are the causes?

3. How is the problem defined?

\section{Step 3: Generate a sustainable future vision}

1. What are the demands for the future vision?

2. How does the future model of urbanism look like?

3. How is the future model of urbanism different from the current model of urbanism?

4.What is the rationale for developing the future model of urbanism?

5. Which sustainability problems have been solved and which technologies have been used in the future vision?

\section{Step 4: Conduct empirical research}

1. What is the justification for the methodological framework to be adopted?

2. Which category of case study design is most relevant to investigating the dimensions of the future model of urbanism?

3. How many case studies are to be carried out and what kind of urban phenomena should they illuminate?

4. To what extent can this investigation generate new ideas and illustrate the theories applied and their effects, as well as underpin and increase the feasibility of the future vision?

\section{Step 5: Specify and Integrate the components of the future model of urbanism}

1. What urban and technological components are necessary for the future model of urbanism?

2. How can all these components be integrated into a framework for strategic sustainable urban development planning?

3. What are the key benefits, potentials, and opportunities of the future model of urbanism?

\section{Step 6: Perform backwards-looking analysis}

1. What built infrastructure changes are necessary for achieving the future vision?

2. What sustainable urban infrastructure changes are necessary?

3. What smart urban infrastructure changes are necessary?

4. What social infrastructure changes are necessary?

5. What technological infrastructure changes are necessary?

6. What institutional changes are necessary?

Source: Bibri 2020d, p.18)

smart sustainable in the era of big data. Accordingly, it articulates strategic thinkingthe why-behind both the vision of the future and the plan for getting there.

\section{Descriptive case study}

The descriptive case study approach was applied in the four case studies to investigate the prevailing models of sustainable urbanism and the emerging models of smart urbanism (Step 4). The intention of this investigation is to specify the underlying 


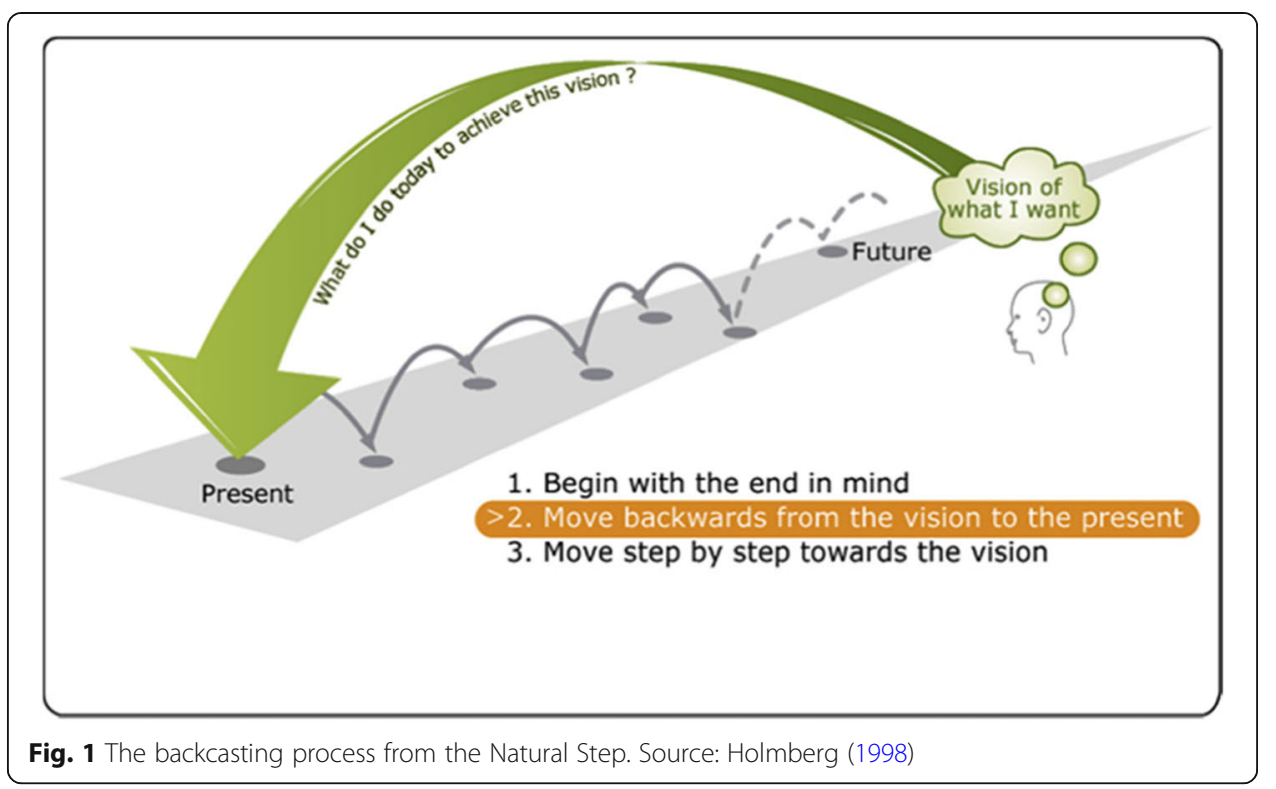

components of the future model of urbanism in terms of its core dimensions, strategies, and solutions, and then to integrate these components into an applied theoretical framework for strategic sustainable urban development planning (Step 5). This is in turn intended to inform and guide the strategic planning process of transformative change towards sustainability, which represents the novel model for data-driven smart sustainable cities of the future (Step 6). This paper relates to the institutional aspects of such process.

The case study is a descriptive qualitative methodology that is used as a tool to study specific characteristics of a complex phenomenon. The descriptive case study approach, as defined by Yin $(2014,2017)$, was identified as the most suitable methodology for the empirical phase of the futures study. This methodology has been chosen considering the nature of the problem being investigated, the research aim, and the present state of knowledge with respect to the topic of data-driven smart sustainable cities. In this context, it involves the description, analysis, and interpretation of the four urban phenomena in question in terms of their characteristics, with a particular focus on the prevailing conditions pertaining to plans, projects, and achievements. That is, how the selected cities behave as to what has been realized and the ongoing implementation of plans based on the corresponding practices and strategies for sustainable development and technological development. To obtain the knowledge sought to be gained, a five-step process tailored to each of the four case studies conducted was adopted (see Table 2):

The case studies examine contemporary real-world phenomena and seek to inform the theory and practice of data-driven smart sustainable urbanism by illustrating what has worked well, what needs to be improved, and how this can be done. They are particularly useful for understanding how different elements fit together and (co-)produce the observed impacts in a particular urban context based on a set of intertwined factors and actors.

\section{Results}

The focus of the results in this paper is on the institutional changes related to the novel model for data-driven smart sustainable cities of the future developed by Bibri and 
Table 2 A five-step process tailored to the four case studies conducted

\section{Compact Cities}

- Using a narrative framework that focuses on the compact city model and its contribution to the three goals of sustainability as a real-world problem and that provides essential facts about it, including relevant background information

- Introducing the reader to key concepts, strategies, practices, and policies relevant to the problem under investigation

- Discussing benefits, conflicts, and contentions relevant to the problem under investigation

- Explaining the actual solutions in terms of plans, the processes of implementing them, and the expected outcomes.

- Offering an analysis and evaluation of the chosen solutions and related issues, including strengths, weaknesses, tradeoffs, and lessons learned.

\section{Eco-Cities}

- Using a narrative framework that focuses on the eco-city as a real-world problem and provides essential facts about it, including relevant background information

- Introducing the reader to key concepts, models, and design strategies relevant to the problem under investigation

- Discussing benefits and research gaps and issues relevant to the problem under investigation

- Explaining the actual solutions in terms of plans, the processes of implementing them, and the expected outcomes

- Offering an analysis and evaluation of the chosen solutions and related issues, including strengths, weaknesses, tradeoffs, and lessons learned.

\section{Data-Driven Smart Cities}

- Using a narrative framework that focuses on the data-driven smart city as a real-world problem and provides essential facts about it, including relevant background information

- Introducing the reader to key concepts, technologies, and data-driven smart sustainable urbanism processes and practices relevant to the problem under investigation

- Providing an overview of the literature review previously conducted in relation to the study, which delivers a comprehensive, state-of-the-art review on the sustainability and unsustainability of smart cities in relation to big data technology, analytics, and application in terms of the underlying foundations and assumptions, research problems and debates, opportunities and benefits, technological developments, emerging trends, future practices, and challenges and open issues

- Explaining the actual solutions in terms of plans, the processes of implementing them, and the expected outcomes

- Offering an analysis and evaluation of the chosen solutions and related issues, including strengths, weaknesses, tradeoffs, and lessons learned.

\section{Environmentally Data-Driven Smart Sustainable Cities}

- Using a narrative framework that focuses on data-driven smart solutions and their role and potential in improving and advancing environmental sustainability in the framework of the smart sustainable city as a realworld problem, and provides essential facts about it, including relevant background information.

- Introducing the reader to key concepts, core enabling technologies, infrastructures, landscapes, frameworks, as well as urban operating systems and urban operations centers, all with relevance to the problem under study.

- Identifying the commonalities and differences between the two cities with respect to the emerging technologies

- Explaining the actual solutions in terms of plans and visions, the processes of implementing them, and the realized and expected outcomes

- Offering an analysis and evaluation of the relevant solutions and related issues, including strengths, weaknesses, and lessons learned.

Bibri 2020d, p. 25)

Krogstie (2021) and the associated direct and indirect effects on the balancing and advancement of sustainability goals. Therefore, this paper is an integral part of the analytical side of the backcasting process, i.e., the specific step of looking back from the desired future to the present to determine the decisive steps on how to attain the future vision. Prior to this, Bibri and Krogstie (2021) identify a series of actions and measures 
pertaining to built infrastructure, sustainable urban infrastructure, smart urban infrastructure, social infrastructure, and technological infrastructure. These constitute the core dimensions of the landscape of the data-driven smart sustainable city of the future, and are associated with the transformations that are necessary for reaching the future vision. In order to bring about these transformations, a number of strategies and pathways were developed in the form of recommendations based on the case study research carried out on six of the ecologically and technologically leading cities on Europe. This paper as a final work of the backcasting study distills the core institutional practices and competences in terms of what has been enhanced, created, and established on the same basis in the form of actions, measures, and functions.

Benefits, potentials, and opportunities for environmental, social, and economic sustainability

One of the goals that is necessarily present in most backcasting studies is analyzing the benefits, potentials, and opportunities of the future vision. The desired vision of the future as constructed by Bibri and Krogstie (2020d), p. 89) is as follows:

"A form of human settlements that secures and upholds environmentally sound, economically viable, and socially beneficial development through the synergistic integration of the more established strategies of sustainable cities and the more innovative solutions of data-driven smart cities towards achieving the long-term goals of sustainability."

At the core of the future vision is the idea of retaining the best of what we already have that have been successfully enacted in real-world cities, making use of the things that have been demonstrably better in the past, while being selective in adopting the best of what is emerging and promising, making use of the things that will add a whole new dimension to sustainability in terms of harnessing its synergic effects, balancing its dimensions, and thus boosting its benefits. This entails combining and integrating the prevailing models of sustainable urbanism and the emerging models of smart urbanism in terms of their strategies and solutions. The benefits, potentials, and opportunities that can be offered by each of these models are presented next.

\section{Eco-cities}

The eco-city has emerged, over the last four decades or so, as a response to the environmental challenges of sustainable development. Register (2002) defines an eco-city as "an urban environmental system in which input (of resources) and output (of waste) are minimized." According to Jabareen (2006, p. 47), it is an umbrella term that "encompasses a wide range of urban-ecological proposals that aim to achieve urban sustainability. These approaches propose a wide range of environmental, social, and institutional policies that are directed to managing urban spaces to achieve sustainability."

The eco-city focuses more on the environmental dimension of sustainability in terms of the natural environment and ecosystems than on the economic and social dimensions of sustainability (e.g., Mostafavi and Doherty 2010; Holmstedt et al. 2017; 
Rapoport and Vernay 2011). There are many models of the eco-city according to an extensive literature review conducted by Bibri (2020b). These models can be caterogarized into three types: type 1 emphasizes passive solar design, type 2 combines passive solar design and greening, and type 3 focuses on green energy technologies and/or smart energy and environmental technologies (Table 3).

Accordingly, while the benefits of the eco-city are mostly of an environmental nature, they also include some economic benefits pertaining to green technologies (Table 4).

\section{Compact cities}

The compact city is the most advocated model of sustainable urban form due to its ability to deliver the expected benefits of environmental, economic, and social sustainability, yet to varying degrees. So, when strategically planned and well-designed, the compact city becomes able to support the balancing of the three dimensions of sustainability through such design strategies as compactness, density, multidimensional mixed-land use, sustainable transformation, and green open spaces (e.g., Bibri 2020c; Burton 2002; Dempsey 2010; Hofstad 2012; Jenks and Jones 2010; OECD 2012). Burton (2002) describes the compact city as "a relatively high-density, mixed-use city, based on an efficient public transport system and dimensions that encourage walking and cycling." Table 5 presents the key benefits of the compact city in relation to the three dimensions of sustainability.

\section{Data-driven smart cities and environmentally data-driven smart sustainable cities}

The data-driven city is an emerging paradigm of smart urbanism, and the environmentally data-driven city is an emerging paradigm of smart sustainable urbanism. The former tends to use advanced solutions to improve the different aspects of sustainability, attempting to cover environmental, economic, and social aspects of sustainability (Bibri and Krogstie 2020b; Nikitin et al. 2016; Noori et al. 2020). According to Nikitin et al. (2016), a data-driven city is characterized by the ability of city management agencies to use technologies for generating, processing, and analyzing data flows in order to develop and implement solutions for improving the living standards of citizens thanks to the development of social, economic and ecological areas of the urban environment. In other words, it is a digitally instrumented, datafied, and networked city that enables large-scale computation to extract useful knowledge for decision making purposes related to the different aspects of operational management and planning development in line with the goals of sustainability.

The latter is associated with the environmental dimension of data-driven smart sustainable cities. A data-driven smart sustainable city is a city that as increasingly

Table 3 Three types of the common eco-city models

\begin{tabular}{lll}
\hline Type $\mathbf{1}$ & Type $\mathbf{2}$ & Type $\mathbf{3}$ \\
\hline - Eco-village & - Eco-City & - SymbioCity \\
- Solar city & - Eco-District & - Carbon Neutral City \\
- Solar village & - Environmental City & - Zero Energy City \\
- Cohousing & - Green City & - Zero Carbon City \\
& - Garden City & - Low Carbon City \\
& - Sustainable Neighborhood & - Ubiquitous Eco-City \\
& - Living Machines & - Smart Eco-City \\
& & - Data-Driven Smart Eco-City
\end{tabular}


Table 4 The key environmental and some economic benefits of the eco-city

\section{Green infrastructure}

- Providing ecosystem services:

Air quality

Recreation

Climate mitigation and adaptation

Flood risk mitigation by slowing and reducing stormwater discharges

Temperature regulation

Passive irrigation

Biodiversity and habitat

Stormwater management

- Managing water by mimicking the natural water cycle

- Improving the quality of water by protecting local waterways from stormwater pollutants

- Replacing or complementing technical systems

- Making urban areas more pleasant by improving their design aesthetics

- Improving economic attractiveness through greening, e.g., high land values which create a willingness to invest and develop urban areas

- Enhancing community safety and the quality of life

- Removing harmful substances from the air and thus increasing its quality

- Reducing stress as linked to mental and physical well-being and the development of illness.

- Providing favorable conditions for healthier life

- Reducing traffic noise and providing cooler temperatures and greater diversity

\section{Sustainable energy systems}

- Maximizing energy efficiency

- Conserving energy by combining heat and power provisions

- Reducing $\mathrm{CO} 2$ emissions due to the use of renewable energy sources:

Wind, solar, and hydropower produce little or no air pollution

Biomass and geothermal do emit air pollutants, but at much lower rates than most fossil fuels

- Enabling districts to become fossil fuel-free, zero-carbon, and climate positive

- Reducing energy costs and ecological impact to the lowest possible level

- Diversifying energy supply and reducing dependence on imported fuels

- Clean and cheap to run

- Mitigating large-scale failure due to a distributed, modular fashion deployment

- Distributing electricity with less complex and time-consuming infrastructural development thanks to the quick rollout of technologies in response to the needs of the city during critical events or complex emergencies

\section{Sustainable waste management system}

- Decreasing the landfilling of household waste and other waste

- Rising the recovery of material for reuse and recycling, as well as of energy in the form of heat and electricity

- Generating biogas fuels from food sludge and other organic waste as well as from wastewater and sewage

- Converting food waste into bio-fertilizer that can replace artificial fertilizers

- Mitigating Greenhouse Gases (GHG) emissions from waste incineration, irrespective of the quantity of the incinerated waste

- Reducing he environmental impact of waste management: GHG emissions and emissions of hazardous substances (e.g., organic pollutants, heavy metals)

- Reducing the noise and congestion caused by garbage collection trucks thanks to the bins connected directly to the underground repositories, where waste is sucked out by vacuum chutes via underground pipes

\section{Sustainable materials}

- Increasing productivity 
Table 4 The key environmental and some economic benefits of the eco-city (Continued)

- Improving health and quality of life

- Decreasing waste generation

- Using materials in more effective ways

- Reducing air pollution

- Avoiding noise pollution

Green technology development

- Spurring green-tech innovations

- Increasing green-tech manufacturing and export

- Stimulating R\&D projects and opportunities

- Inspiring entrepreneurship and creating startups

- Increasing industrial and technological investments

- Providing a significant number of jobs and opportunities for skill development

- Stimulating cooperation between government, industry, and academia

- Providing opportunities for international collaboration among urban actors

composed of and monitored by ICT of pervasive and ubiquitous computing and thus has the ability to use the IoT and big data technologies to generate, process, analyze, and harness urban data for the purpose of creating deeper insights that can be leveraged to make strategic decisions that accurately address the problems and issues related to sustainability and urbanization. A data-driven smart sustainable city is depicted as constellations of instruments across many scales that are connected through multiple networks characterized by high speed and intelligence, which provide continuous data regarding the different aspects of urbanity in terms of the flow of decisions about the environmental, economic, social, physical, and spatial forms of the city, supported by urban intelligence functions.

Furthermore, the two emerging models of urbanism are evolving into real-time functioning cities based on the data routinely collected from the sensors deployed across urban environments, which can provide useful information about longer term changes (see, e.g. Ameer and Shah 2018, Batty et al. 2012; Kitchin 2014; Nikitin et al. 2016; Shahrokni et al. 2014a, b; Rathore et al. 2016, Sinaeepourfard et al. 2016). As such, they involve not only benefits, but also potentials and opportunities that are yet to be exploited and explored respectively (Table 6).

\section{Institutional transformations: practices and competences}

To boost the effects of sustainability through combining the benefits, potentials, and opportunities of the prevailing models of sustainable urbanism and the emerging models of smart urbanism requires major institutional transformations and sociotechnical transitions. There is a growing perception that the centripetal movement of data-driven smart sustainable interests, ideas, and considerations in urban strategies, technological innovations, and institutional developments can have a significant impact on data-driven smart sustainable-induced processes of transformation in the core practices, primary operations, and central institutions of modern society. This is what the data-driven smart sustainable city of the future entails as a strategic roadmap to transformational change. This process is designed to create major changes in the processes 
Table 5 The contribution of the compact city to the three goals of sustainability

\section{Environmental sustainability}

- Lowering per capita rates of energy use and $\mathrm{CO} 2$ emissions through district-wide energy utilization and local energy generation

- Conserving energy by combining heat and power provisions made possible by population densities

- Lowering energy consumption and reducing pollution due to the proximity to workplaces, services, facilities, and public spaces

- Reducing car dependency and thus CO2 emissions through promoting a walking and cycling environment

- Decreasing travel needs and costs and shortening commute times

- Minimizing the transportation of energy, materials, water, and products, thereby reducing CO2 emissions due to the compactness of the built form

- Optimizing the efficiency of public transport by promoting transit-oriented development in built-up areas

- Limiting the consumption of building and infrastructure materials

- Reducing the pressure on ecosystem services and biodiversity provided by green and natural areas

- Limiting the loss of green and natural areas

- Protecting rural and agricultural land from further development through the optimum use of land resources

\section{Economic sustainability}

- Supporting local services and businesses through population densities by providing a larger customer basis for commercial activities

- Revitalizing city centers through the promotion of densely built dwellings, shops, businesses, and accessible infrastructure and facilities

- Extending and enhancing public transportation infrastructure and facilities

- Creating proximity between workers and their workplaces, which results in higher productivity due to shorter travel time for workers

- Greater diversity of employers and thus job possibilities

- Increasing the likelihood of workers finding jobs that match their skills, which also results in higher productivity

- Greater productivity due to more diversity, vitality, innovation, and creativity

- Attracting skilled labor force by high quality of life due to better access to a diversity of local services and jobs

- Maintaining the diversity for choice among workplaces, service facilities, and social contacts

- Requiring less and cheaper per capita infrastructure provision due to more efficient public service delivery

\section{Social sustainability}

- Creating a better quality of life through more social interaction, community spirit, and cultural vitality due to the access by proximity to facilities, workplaces, public spaces, public transportation, as well as the opportunity for walking and cycling

- Reducing crime and providing a feeling of safety through natural surveillance

- Improving social equity through better access to services and facilities and flexible design of housing in terms of mixed forms and affordability

- Maintaining public service level for social welfare by improved efficiency

- Greater accessibility due to lower cost enabled by shorter intra-urban distances

- Lowering transport costs, higher mobility for people without access to a car, and improved human health due to more cycling and walking

- Enhancing social cohesion through a sense of belonging and connectedness

- Supporting human, psychological, and physical health through ready access to open green space, walkability in neighborhoods, and social contact

- Enhancing livability in terms of social stability and cultural and recreational possibilities

- Healing spatial segregation by forging the physical links and bridging barriers between communities 
Table 6 The key benefits, potentials, and opportunities of the data-driven smart city and the environmentally data-driven smart sustainable city

\section{Transport and traffic management}

- Reducing energy usage and harmful emissions

- Providing the opportunity to alter demand for carbon-intensive vehicles using disincentives

- Increasing and maintaining safety for vehicle drivers by detecting accidents and responding timely to critical events through alerts

- Predicting traffic conditions for decreasing congestion by directing vehicles to alternative roads

- Reducing noise pollution through smart traffic lights and smart parking

- Improving the security and reliability of the overall transport system

- Encouraging and attracting people to cycle thanks to dynamic signage system, thereby reducing $\mathrm{CO} 2$ emissions resulting otherwise from more polluting forms of energy-intensive transport

- Enhancing mobility for citizens and thus increasing the level of their life satisfaction

- Providing the opportunity for contactless payment and thus minimizing environmental impacts

- Providing the opportunity for obtaining more detailed information on transport and mobility thanks to the unified public transport system

- Tracking traffic occupancy for planning public transport routes in a more flexible way

- Identifying the user priorities of public transport areas and developing new routes in response to new demands

- Improving, re-engineering, or developing transport infrastructure based on historical mobility and congestion data

- Decreasing the need for parking spaces on the streets through car sharing system

- Supporting equity and inclusion through socially sustainable public transport thanks to smart mobility apps

- Providing information to passengers about traffic occupancy/irregularities of public transport, which allows them to plan their way more efficiently

\section{Smart power grid}

- Improving the transmission efficiency of electricity

- Optimizing distribution networks in terms of energy demand/supply

- Restoring after and reacting timely to potential disturbances in power supply

- Reducing operation, maintenance, and management costs

- Integrating different systems of renewable energy

- Reducing electricity bills and thus saving money as well as balancing the electricity system through efficient electricity networks

- Making storage decisions based on the monitoring of power generation and power demands

- Helping governments to react promptly to emergencies, critical events, or natural disasters, e.g., severe storms, earthquakes, and large solar flares, through adding resiliency to large-scale power systems

- Curbing energy usage, conserving energy, reducing costs, and maximizing the transparency and reliability of the energy supply chain

- Avoiding potential power outages resulting from high demand on energy using dynamic pricing models for power usage by increasing charges during peak times to smooth out peaks and applying lower charges during normal times.

- Avoiding carbon-intensive peaks using new ways of coordination with regard to the overall ensemble of users and consumers.

- Supporting decision-making pertaining to the generation and supply of power in line with the actual demand of users and consumers

- Improving coordination and planning around power generation from renewable plants depending on wind or sun.

- Monitoring and analyzing energy consumption in real time across multiple spatial scales and over different temporal scales

\section{Smart buildings}

- Providing the potential for energy efficiency and GHG emissions reductions through such functions as:

- Highly advanced automatic systems for efficient and natural lighting 
Table 6 The key benefits, potentials, and opportunities of the data-driven smart city and the environmentally data-driven smart sustainable city (Continued)

\footnotetext{
- Temperature control

- Window and door operation

- Smart appliances

- Keeping the building's climate within a specified range

- Reducing energy consumption and energy costs

- Guaranteeing safety and security
}

- Providing the potential for decreasing heat demand and consequent GHG emissions by means of retrofitting residential buildings

- Assessing energy demand from large-scale retrofitting and exploring its impact on the supply side, thereby enabling more precisely targeted and better coordinated energy efficiency programs

\section{Smart meters and energy monitors}

- Allowing consumers to manage their energy usage based on what they actually need and afford by having access to live energy prices and adjusting their usage accordingly

- Enabling consumers to remotely control their home appliances and devices by means of such advanced functions as scheduling, programming, as well as reacting to contextual situations

- Allowing for self-optimization and self-control of energy consumption through integrating sensing and actuation systems in different kinds of appliances and devices for balancing power generation and usage

- Providing insights into how the energy flows can be influenced by the consumer behavior thanks to the inhouse sensors that can report data on energy-using appliances

- Balancing electric loads and reducing power outages

- Allowing for dynamic pricing which lowers or raises the cost of electricity based on the current demand

- Providing homeowners with convenience and cost savings

- Offering homeowners sophisticated level of preprogrammed preferences in terms of turning on some appliances based on the amount of the energy consumed within a day, week, or month

\section{Smart environmental monitoring}

- Reducing the time needed for waste collection as well as the operating time of disposal machines

- Curbing fuel consumption and costs

- Reducing the number of waste disposal vehicles and containers and related service costs

- Reducing the level of harmful emissions through route optimization

- Decreasing noise pollution generated by waste disposal vehicles

- Providing health benefits and decreasing health risks through preventing the accumulation of waste

- Using historical and movement data

- Using historical data on disposed waste (places and volumes) for installing new waste containers

- Distributing the resources and logistics more efficiency, thereby significantly reducing the operational and infrastructural costs of waste collection system

\section{Smart management of waste collection}

- Developing a variety of preventive systems and measures for environmental quality and implementing them in a timely manner

- Enabling public authorities to observe the condition of the air and to forecast about its pollution

- Enabling government and non-governmental bodies to take decisions based on a more informed understanding of the quality of the environment

- Complementing energy efficiency solutions with respect to GHG emissions reductions

- Informing citizens and other city stakeholders about GHG emissions

- Ensuring companies' compliance with environmental regulations and evaluating the efficiency of the newly installed systems as well as the health of employees

- Evaluating the performance of environmental regulations and enforcements, whether they are working as anticipated, so that the government can take action to change the regulatory framework

- Stimulating research opportunities on the effects of certain pollutants on human, wildlife, or aquatic life so to create treatment procedures 
Table 6 The key benefits, potentials, and opportunities of the data-driven smart city and the environmentally data-driven smart sustainable city (Continued)

- Finding risks to human and wildlife, scoping to population migration from high-density areas to low density areas, and restricting GHG emissions

- Identifying environmental stress, understanding environmental patterns, and assessing the effectiveness of strategies and programs

- Collecting critical information to make better policy decisions to reduce GHG emissions, as well as to guide citizens on making their own efforts in this regard

- Allowing the interpretation of the ambient air data based on the spatial and temporal representativeness of the data gathered and on the health risks involved in the exposure to the monitored levels

- Allowing the comparison of the different districts of the city in terms of various air pollutants

- Publishing hourly more detailed information for each pollutant in absolute value, and designing daily values for drawing a more complete picture at monitoring the level of pollution in the city

- Allowing users to explore the available information at maximum level due to the opportunity to gather information about the status of the atmosphere

- Allowing companies and enterprises in the industry to get an idea about the air quality, which makes it possible to make decision on the implementation of preventive measures for reducing pollution. This leads to the maximisation of their productivity in the long-term

- Allowing industries to access the air pollution forecasts, which simplifies the decision-making process in the manufacturing environment

- Predicting trends of the presence of air pollutants in the atmosphere

- Coping with the environment and lowering air and noise pollution levels to enhance the quality of life

\section{Smart street lighting}

- Facilitating many innovative applications related to traffic, mobility, air and noise pollution, parking, safety, and public Wi-Fi connectivity, just to name a few

- Enhancing the environmental performance and energy efficiency of the essential infrastructure of the city

- Optimizing the efficiency of the public-lighting installations in terms of operational and maintenance costs

- Reducing collision and the risk of collisions with cyclists and other vulnerable road users

\section{Smart urban metabolism}

- Providing holistic analysis of energy and material pathways to conceive of management systems and technologies that allow for the reintegration of natural processes, increasing the efficiency of resource use, and the conservation and production of energy

- Providing long-term opportunities in terms of enabling a new understanding of the causalities that govern urbanism

- Allowing citizens and city officials and stakeholders to receive real-time feedback on the consequences of their choices in a systematic way

- Understanding the GHG emissions resulting from the consumption of electricity, heat, water, and the production of waste

- Allowing the follow-up and evaluation of the evolution of urban metabolism, and facilitating the identification of the cause-and-effect relationships of the metabolic flows

- Providing rich datasets on energy and material flows at the city level in terms of both production- and consumption-based approaches

\section{Smart management of urban infrastructure}

- Improving incident management

- Enhancing emergency response coordination

- Mitigating risks and responding timely to critical events or unfavourable conditions

- Enhancing safety and service quality

- Reducing operational and maintenance costs

- Improving resources and logistics efficiency

- Reducing negative impacts on the environment

- Identifying, predicting, and responding to longer-term urban infrastructure needs 
Table 6 The key benefits, potentials, and opportunities of the data-driven smart city and the environmentally data-driven smart sustainable city (Continued)

\section{Smart citizens: participation and consultation}

- Empowering citizens for community engagement and co-creation

- Improving the level of satisfaction and increasing the level of confidence and trust among citizens in the city administration

- Promoting widespread participation through new technologies that are essentially network-based and enable extensive interactions across many urban domains as well as spatial scales

- Enhancing equity and fairness and attaining a better quality of city life through new technologies that offer the prospect of ending the digital divides

- Enabling the citizenry to blend their personal knowledge with the knowledge of technology experts

- Informing political participation at all levels

- Engaging the citizenry in city planning, development, and governance

- Making it easier for citizens to find out about planning issues and improving the efficiency and effectiveness of local planning

- Enabling the planning service to perform better with fewer resources for property developers, architects, surveyors, and planning consultants

- Improving the transparency of the city management

- Providing the opportunity to track the quality of work of the management companies and contractors engaged in the provision of urban amenities and services, and to perform corrective actions in the work of local authorities

- Enabling citizens to participate in the technology and policy of the city through various platforms, such as classrooms for leaning, spaces for innovation, co-innovation centers, and participatory and democracy platforms

- Providing services by public agencies remotely and mobile kiosks, such as receiving certificates, publishing complaints, and obtaining necessary information. This improves the convenience of public services

- Determining trends in public opinion to be considered when forming urban development programs and initiatives

\section{Smart public safety}

- Empowering decision-makers to prepare for, respond to, and recover from natural disasters

- Increasing safety by identifying risks, threats, and vulnerabilities and providing early warnings

- Preventing adverse effects on public health by notifying citizens to evacuate or avoid certain urban areas

- Enhancing risk assessment and hazard identification to provide immediate responses

- Improving security by allowing or denying access to certain individuals to public places, as well as preventing potential unrest

- Providing the opportunity for increasing urban resilience

- Informing the responsible public and private actors of transportation-related safety and health issues to make improvements

\section{Smart healthcare}

- Electronization of medical services:

- Making medical services more accessible to the public

- Accelerating the process of customer services

- Allowing more flexible arrangement of visits to doctors and obtaining the right specialist

- Enabling physicians to get rid of paper routine and to always have access to data about patients, the history of their diseases, and the medicines they take

- Providing the municipal administration with reliable and efficient tools for analysis of medical institutions activities

- Providing the administration with the opportunity of managing resources more efficiently

- Enabling transparent reporting and planning for future purchases and saving costs for the city budget.

- Large-scale electronization system:

- Improving the comfort of using public medical services

- Optimizing the availability and workload of physicians in medical institutions 
Table 6 The key benefits, potentials, and opportunities of the data-driven smart city and the environmentally data-driven smart sustainable city (Continued)

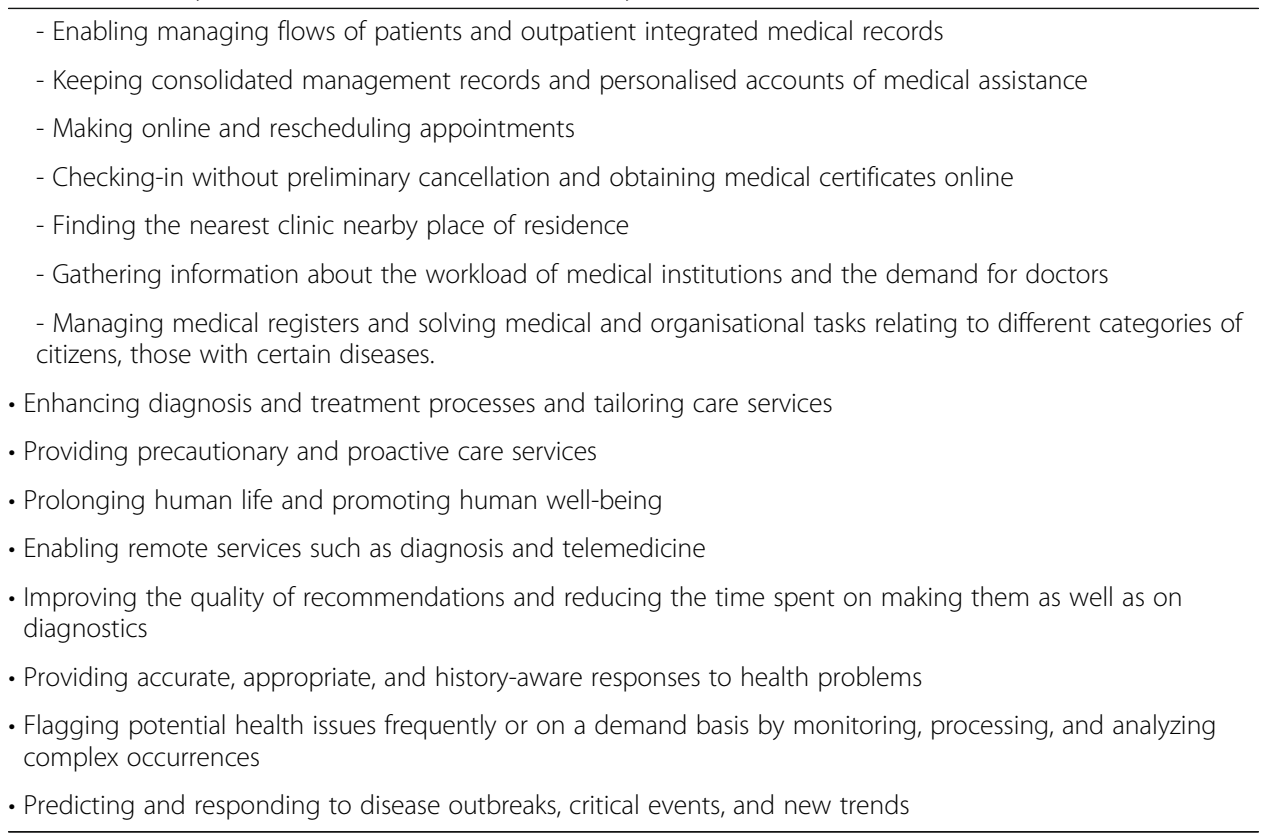

of sustainable cities and the behaviors of their actors, as well as to produce significant improvements in their performance. The focus in this paper is on the institutional aspects of this process, which affect revolutionary change within modern cities. Generally, institutional transformation denotes profound changes within institutions in the basic values, and beliefs that are dominant, as well as in the rules and regulations that lead to certain outcomes. In other words, at its deepest level, it refers to changes in the ideas, interests, and considerations that govern institutions, which in turn lead to changes in practices and related apparatuses. Institutional transformation explains the change of institutions that govern human interactions and paths of development in society. Institutions are defined as "actions, rules, social structures and practices that persist over time and are features of social aggregate that are larger than a single organization" (Murmann 2003).

It is within the remit of institutions to facilitate the implementation of data-driven technology solutions in city operational management and development planning to improve and advance sustainability through regulatory frameworks and social norms. There is a strong institutional support and commitment to big data technology-industry associations and consortia, business communities, research communities, policy networks, regulatory and legal bodies, and governmental agencies-within sustainable urbanism and smart urbanism given its untapped potential, rapid expansion, and wide success as to advancing scholarly research and enhancing social practice (see Bibri 2019c for a detailed discussion).

\section{Supporting the balancing of the three dimensions of sustainability}

Sustainable cities are in a constant state of unprecedented transformative changes in response to emergent internal and external factors, such as climate change, urbanization, 
technological shifts, economic crises, pandemics, and demographic changes. Managing sustainable cities is a very complex function that encompasses strategies, approaches, activities, and instruments that make them work. This means that:

- Their infrastructures are accessible and functional

- Their energy systems are sustainable and efficient

- The needed natural resources and public services are available and equitably distributed among citizens

- Their designs are efficient and scalable

- Their plans are comprehensive, dynamic, and continuous

- The interests of the different stakeholders, especially citizens, are well represented and count in decision making processes and in future developments

- Their economy is sustainable and prosperous.

All these aspects of sustainable development need to be planned and managed at a city administration level, but with a wider context in mind. It is important for a city government in collaboration with development agencies to make progress in developing flexible and action-oriented strategies. These should emphasize the interconnectivity of sectors and integrate a wide range of players while relying on advanced ICT as essentially network-based and an enabler of an extensive interaction across many sectors, supported by institutional structures and governance models.

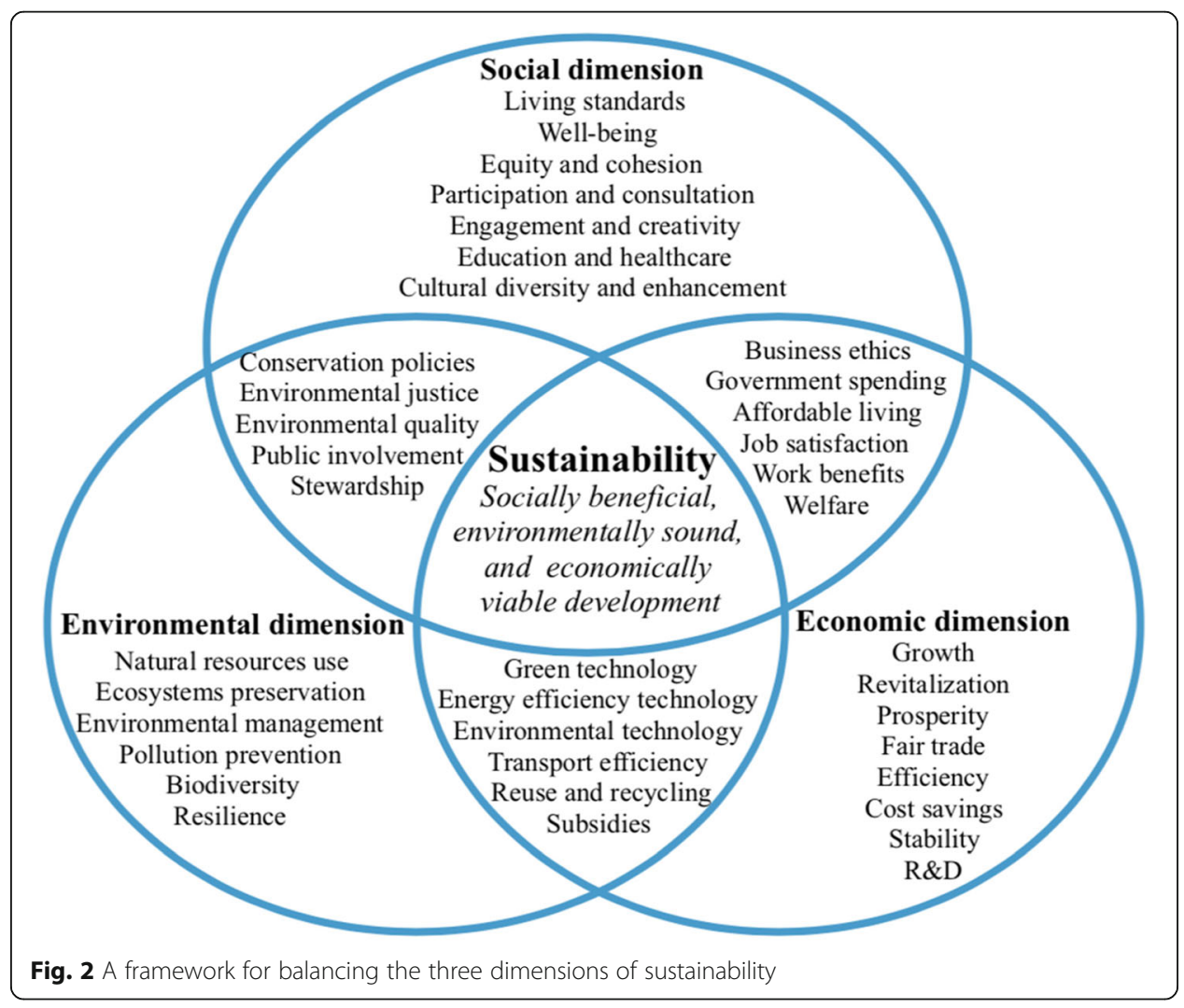


It is crucially important to ensure that the institutional practices and competences in the data-driven smart sustainable city of the future support the balancing of the environmental, economic, and social goals of sustainability (Fig. 2). This implies that concrete and distinct actions and measures should be in place as part of a coordinated framework to make the most of the opportunities offered by sustainable development and supported by technological development. The core institutional practices and competences needed in this regard are presented in Table 7 in the form of actions and measures, organized in accordance with the three dimensions of sustainability.

\section{Introducing modern technology and adopting applied solutions in the city management}

All traditional mechanisms of the city management (administration, organization, and planning) are gradually replaced with digital mechanisms enabling and supporting data-driven decision making. Big data analytics improves the quality and speed of decision making. Data-based city management relies on urban computing and intelligence for implementing the data-driven technology solutions developed for the various spheres of the city administration, including:

- Transport management

- Traffic management

- Street lighting management

- Mobility management

- Waste management

- Energy management

- Environmental monitoring

- Building management

- Public safety

- Healthcare and education

Urban computing and intelligence bridges the gap of ubiquitous sensing, intelligent computing, cooperative communication, and large-scale data processing and management technologies to create novel solutions to enhance urban forms, urban infrastructures, urban environments, and urban services. Such solutions can be developed through cloud and fog computing or city own facilities, the IoT devices, intelligent networks, artificial intelligence, and big data analytics.

In addition, data-based city management involves a number of agencies that use technologies for generating, processing, and analyzing data to adopt solutions for improving sustainability, efficiency, resilience, equity, and the quality of life for citizens. As such, it builds on the concept of the smart city: an urban area that uses different types of technologies to collect and analyze data to gain deep insights that can be applied to manage assets, resources, and services efficiently, thereby optimizing and enhancing urban operations and functions. However, in the current climate of intensive urban growth, the quality of the urban environment plays an increasingly key role in improving wellbeing. Data-based city management is a basic driver for the transformation of urban services and innovations, and will dramatically change the principles of managing the urban environment. It entails the 
Table 7 The core institutional practices for supporting the balancing of the three dimensions of sustainability

\section{Sustainability \\ Environmental Dimension}

Economic

Dimension

Social Dimension

\section{Institutional Practices and Competences}

- Make green structure plans that map the city's green resources by assessing their natural and recreational qualities

- Use green structure plans as a means to enhance and integrate the available knowledge of the green structure and create the opportunity to gain a coherent view of its totality, as well as to focus attention on the city's merits and shortcomings in regard to green structure preservation

- Introduce balancing principles to compensate for any potential loss of natural and agricultural land with a new or reinforced land (e.g., recreational land), so the final result is more valuable

- Establish a research center for environmental sustainability

- Establish an innovation center for green energy technology

- Transform the innovation center into an international meeting place where the city, the business community, and the research community work collaboratively to profile and demonstrate know-how in green energy technology

- Establish a research and innovation center for zero emission neighbourhoods

- Establish a living lab for zero-emission/net-zero energy buildings as a multipurpose experimental facility to study various technologies and design strategies in a real-world living environment

- Establish a research and innovation center for green, passive, and low energy buildings

- Support green energy technology innovation projects through funding schemes, advocating the adoption of environmentally friendly products and services, organizing symposiums on environmental innovations, encouraging local environmental programs, and devising comprehensive environmental plans

- Create arenas where industry experts, businesses, politicians, and citizens meet to discuss environmental problems and potential solutions

- Promote regional collaboration to enhance business development

- Make detailed regular plans for business development where the economic goals of sustainability are coupled with the targeted measures. This relates to the balanced scorecard, a strategic management performance metric used to measure and provide feedback to organizations by identifying and improving various internal business functions and their external outcomes

- Make strategic business development plans to guide business and tourism development

- Expand the tourism industry and boost the regional business links

- Use physical planning to adapt the prioritized areas for development to business development

- Create arenas where politicians, business actors, and public servants meet to discuss topical questions and issues

- Support collaboration and networking with business actors to enhance knowledge and information sharing

- Develop higher educational programs that integrate education and research into business development

- Intensify collaboration between businesses, educational institutions, and research centers

- Inspire and stimulate local entrepreneurship by providing financial support and counselling and by organizing contests between, and offering awards to, young entrepreneurs and innovators

- Create various resources to support small and medium-sized enterprises

- Establish a research center for innovation, entrepreneurship, and learning

- Create R\&D projects in light of new city development projects in the medium and long term based on partnerships between government, academia, and industry

- Transform new successful sustainable urban development projects into sites that attract new investments, ventures, study visits, further development initiatives, and international interests

- Ensure collaboration on and alignment with a shared vision of sustainability among companies, organizations, and institutions with different interests and goals

- Make public health plans

- Develop procedures that secure a linkage between urban planning and public health goals 
Table 7 The core institutional practices for supporting the balancing of the three dimensions of sustainability (Continued)

through initiatives to provide access to green and recreational areas, as well as arrangements to improve cycling and walking, thereby enhancing the opportunity to engage people in physical activity

- Ensure that the social sustainability plan plays a prominent role in local policy-making, and constitutes the basis for political debate where solutions to the challenges and issues addressed are sought

- Ensure that plans rest on statistics, indicators, and qualitative data as the basis of knowledge for political decisions

- Make plans on the basis of the areas for improvement identified, and discuss and monitor them on an annual basis. The monitoring to be employed should include a number of issues, such as the number of newly built dwellings, the assortment of dwellings, the affordability of housing, the safety of public spaces, the ability to enhance the quality of life in the city's socio-economically weak and vulnerable areas, the ability to improve the air quality and reduce the noise level, the protection of green and natural areas, and so on

- Develop strategic guidelines for social justice, social inclusion, social cohesion, and social capital so that they can be converted into concrete projects and programs

- Establish a research and innovation center for social sustainability

- Establish a research and innovation center for the loT and people to study how the citizenry can get the most out of the loT as a socially disruptive technology with respect to transportation, accessibility, energy, home automation, living, health, learning, and so on in terms of services

- Establish a research center for ICT for sustainability aiming to contribute to changes in social institutions, social behaviors, social relations, and social perceptions in a sustainable direction

- Establish a research center for sustainable development to contribute to the development of a sustainable society. This contribution includes the shift towards sustainable technical and social systems that meet human needs, such as food, housing, transportation, communication, and recreation

- Create a participatory democracy platform that allows citizens to see and discuss proposals put forward by the city government, and submit their own. Such platform is used to create the city's government agenda, with proposals coming directly from the participating citizens

- Create a city council that allows the provision of services by public agencies remotely and mobile kiosks, where one can receive various certificates, publish a complaint, get necessary information, and so on. This is to improve the convenience of public services received by citizens

- Support and strengthen the technologies that ensure widespread citizen participation by security measures and privacy mechanisms. These should be at the core of the city policy and governance practices associated with the design, development, and implementation of interactive platforms.

- Develop and implement advanced technologies that offer the prospect of ending the digital divide, provided that they do not open up other kinds of divides. It is important to explore how new forms of regulation at the level of urban planning, transport planning, economic development, and community development can be improved using future and emerging technologies

- Establish a number of digital literacy programs and investigate the reasons behind the digital exclusion of minorities and vulnerable groups, with the overall aim of having everyone online, or with the aspiration to be online by 2050

- Develop and implement a unified medical information and analytical system, combining such services as communication center, electronic registry, electronic health record, electronic prescription, disability certificates, laboratory services, and personalized accounts.

- Establish center for social innovation and entrepreneurship to create knowledge and ideas for environmental and social change that will be of relevance to the challenges that the city faces through research, education, and experiential learning. This is important to strengthen the capacity of individuals and organizations to develop innovative solutions to complex problems.

utilization of advanced services and development projects through new technologies to benefit people immensely in different ways and to make cities liveable and attractive, which leads to further developments. It brings cohesion and congruence to urban strategies and unifies the expectations of different urban actors in a way 
that the plans are feasible and adequate to the daily reality of a place, and that facilitates a shared vision of sustainable development.

The technical and institutional competences pertaining to the data-driven smart sustainable city of the future reflect the degree of its readiness to introduce data-driven technology in its management as well as the degree of the implementation of applied data-driven solutions in its management. The degree of readiness is characterized by the availability and development level of the technological infrastructure and competencies needed to generate, transmit, analyze, and visualize data. The degree of implementation demonstrates the extensive use of the applied technology solutions developed for operational management and development planning in relation to the different areas of sustainability. The competences are briefly described next along with their key functions.

Horizontal information platforms Both the data infrastructure and operating system for the city constitute what is called horizontal information platforms, a key competence for performing the core functions of big data analytics. Functionally compatible horizontal information platforms allow the creation of a united ecosystem for the city. They explicitly link together multiple urban technologies and solutions to enable greater coordination of the city systems and domains (Table 8):

Operations centers and dashboards The city systems and infrastructures will become much more tightly integrated and interconnected as manifested in what is called operations centers and dashboards. These draw together and interlink the data generated by the city complex to provide an integrated view and synoptic intelligence of the city (Table 9). The new digital technologies embedded and networked in urban environments will transfer the collected data to a number of control and management systems that can respond in real time to data flows.

Strategic planning and policy office The strategic planning and policy office as an analytical center is key to the management of the city development projects and

Table 8 The key functions of horizontal information systems

- Providing open platforms connecting all the sensors installed in the city and the obtained sensed data Aggregating and standardizing the flows of functional and territorial data from municipal sources, the systems of state control (mobility, energy, noise level, pollution level, etc.), business environment, and other state agencies (hospitals, cultural institutions, universities, schools, etc.), as well as from various detectors and cameras for their subsequent integrated analysis and visualization in 3D format

- Solving the problems of data disconnection in the city through the open operating system integrating and processing the information generated by the city

- Reworking and repackaging the collected data for daily consumption by different stakeholders

- Allowing the city authorities and third party users to gain access to the received data in a more structured and convenient manner for software development

- Providing comprehensive solutions to complex urban problems by integrating the self-contained and unconnected technological solutions and information systems used in the different functional departments of the city

- Improving the efficiency and performance of implemented applied technological solutions

- Allowing the city authorities and other users to take decisions on the optimization of the city activities in the short, medium, and long term 
Table 9 The key functions of operations centers and dashboards

- Using visualization sites to help both expert and no-expert users interpret and analyze information, and to allow citizens to monitor the city for themselves and for their own ends

- Employing integrated, real-time data to track the performance of the city and to communicate the live feeds of real-time information to citizens with respect to a number of areas

- Enabling automated systems to respond to citywide events by making immediate decisions pertaining to various urban domains

- Overcoming urban challenges, keeping citizens up-to-date, and developing applications based on the standardized and published forms of open data

- Creating innovative platforms, promoting big data use and application, introducing data-driven technologies, and providing expert assistance

programs pertaining to the implementation and integration of the compact, ecological, and technological aspects of the landscape of the city, particularly in relation the objectives and targets of sustainable development (Table 10).

Innovation and research centers The main function of innovation and research centers is to develop, test, and implement new solutions for the different areas of sustainability. Accordingly, they involve building, sharing, and continuously enhancing practical knowledge in response to the goals, strategies, policies, and visions of the city (Table 11).

Table 10 The key functions of strategic planning and policy office

- Promoting smart approaches through planning systems-making extensive use of data to guide urban planning and design and to encourage developers to deploy digital infrastructure to future proof new developments

- Analyzing population displacement and movement data for the strategic planning of city infrastructures, districts, and streets, thereby taking into account the emerging demands from the population

- Integrating information on the expectations/uses of the residents of the city districts in the construction of scenarios in response to the need for renewal, redevelopment, and development projects

- Developing master and comprehensive plans based on the analysis of the city data

- Integrating technology solutions and urban design solutions when developing urban plans and urban development projects

- Using a one-stop data analytic hub to bring and weave together data from a variety of city agencies and departments in order to regulate and govern the city and to solve related issues

- Collating and analyzing data from a variety of city agencies and departments to enable the city authorities to make decisions more effectively in the fight against crime and on the provision of public safety and quality of life of the city residents

- Prioritizing, based on data analysis, the development of the municipal system and ways to improve the efficiency and effectiveness in the provision of urban services, enforcement of laws, as well as the transparency of the city authorities. Among the primary directions of the initiatives to deal with in this regard are:

- Support of the city's functions by communication with other city agencies, e.g., adoption of resolutions in the form of models based on data analysis

- Data transfer by establishing a platform for exchange of data among various departments, combining data from different sources of various agencies and third party organisations. This can occur through cooperating with the ICT department and the operations centers of the city

- Creation of open data portal to be available to anyone interested

- Developing and implementing strategies for technological development in the city

- Addressing issues of city-wide coordination and cooperation in the field of technologies, playing a bridging role, and advising various city agencies and departments on technological innovations 
Table 11 The key functions of innovation and research centers

- Creating multidisciplinary teams based on practical know how, long-standing experience, international expertise, and access to global networks

- Enabling interaction and promoting cooperation between scholars, researchers, industry experts, business professionals, and thought leaders to enhance research opportunities, academic excellence, real-world problem solving, and knowledge creation and dissemination

- Providing the ground for developing and testing innovative technological solutions for urban management

- Featuring the latest developments in technologies and solutions and demonstrating how they are applied in real-world settings

- Developing urban intelligence functions for improving and optimizing city operations, functions, services. Designs, and strategies

- Understanding, enhancing, and applying the leading city practices

- Integrating resources and expertise for the benefits of the city through collective intelligence

- Managing, analyzing and visualizing different kinds of projects

- Supporting the city authorities in visioning, strategizing, and implementing sustainable development as a set of objectives and targets

Educational centers and training programs The educational centers and training programs are associated with the creation and accumulation of knowledge and expertise in the areas of urban science, urban informatics, data science, computer science, data-intensive science, and big data analytics and their integration into interdisciplinary fields in relevance to sustainable urban development (Table 12). These disciplines are heavily applied fields where the programs offered by the educational institutions should be adequate for enabling the data scientists, experts, and analysts to perform their tasks. The intention is to provide the city with the competences needed to successfully implement the applied technology solutions to improve and advance sustainability.

Competence centers It is important to establish various competence centers as multidisciplinary and multi-stakeholder research and demonstration arena. These centers should address newer subject areas, where efforts should often be conducted in joint projects with businesses and various societal bodies. As autonomous units, they should maintain close connections with industry and act as liaison offices between the hosting universities in the city and other universities in the country. Competence centers should be created in cooperation with all stakeholders of the quadruple helix at the national level, a solution that needs generous support from the government as well as expertise within the various areas of sustainability and technology. Among the

Table 12 The key functions of educational centers and training programs

- Developing educational programs at the intersection of big data analytics, sustainable development, and urban planning and development

- Providing specialized academic programs within urban analytics, urban computing, urban intelligence, and data-driven sustainable urbanism

- Offering a large number of educational programs with data science and analytics discipline

- Introducing data-driven technologies for city operational management and city development planning

- Implementing initiatives for developing competencies in a number of data science and analytics areas in relation to urban sustainability by conducting seminars and providing trainings to improve the level of the applied technological knowledge in this regard 
Table 13 Competence centers for sustainability

- Center for sustainable built environment

- Center for construction efficiency and sustainability

- Center for traffic management research

- Center for transport management research

- Center for integrated sustainable transportation

- Center for smart grid and energy storage

- Center for integrated renewable solutions

- Center for hybrid and electric vehicles

- Center for smart healthcare research: medical systems and services

competence centers to establish in relevance to the different areas of sustainability are shown in Table 13:

\section{Stakeholders, governance, and policy}

The futures study is concerned with the pathway-oriented category of backcasting (e.g., Bengston et al. 2020; Wangel 2011), which entails identifying the actions and measures that connect a desirable state of the future to the present. At the core of this category in this context is how to bring about transformations to the landscape of the datadriven smart sustainable city of the future (Bibri and Krogstie 2021), supported with institutional practices and competences. Wangel (2011) classifies backcasting into several categories, namely pathway-oriented backcasting (how to change), target-oriented backcasting (what can change), action-oriented backcasting (who could make change happen), and participation-oriented backcasting (to enhance participation and buy-in by stakeholders). Accordingly. a detailed stakeholder analysis would rather be more relevant to action-oriented or participation-oriented backcasting. It is a way of studying a network in order to generate information on the relevant actors, "to understand their behaviour, interests, agendas, and influence on decision-making processes" (Reed et al. 2009), and to identify differing perspectives and avoiding conflicts (Prell et al. 2009). Also, the concept of governance is important when it comes to the actors involved in any transformative change. As argued by Wangel (2011, p. 881) with reference to action-oriented or participation-oriented backcasting, adding governance and actors in the backcasting study makes it "more socio-technically consistent and comprehensive," and can also identify if prevailing social structures restrain change. With the above in mind, the analytical account provided below is meant to help the reader gain some insights into how the concepts of stakeholder and governance together with politics and policy relate to the strategic planning process of transformative change towards sustainability from a general perspective.

Building the data-driven smart sustainable city of the future involves complex sociotechnical constellations and configurations of a variety of urban, technological, scientific, social, political, cultural, and institutional actors interacting with and influencing each other on multiple scales and with different levels of complexity. At the core of this dynamic interplay is the engagement of many stakeholders in continuous dialogue to determine the programs associated with the development and implementation of the data-driven smart sustainable city of the future. Generally, the key stakeholders to be 
involved include: citizens, decision makers, policy makers, planners, developers, architects, experts, scientists, academics, scholars, researchers, professionals, business leaders, industrial engineering gurus, futurists, as well as civil society organizations. The data-driven smart sustainable city of the future is essentially dependent on the initiative by and interest of these stakeholders-that each sees it as of relevance and meaningfulness enough to play a role in a specific area-and that their initiatives should be coordinated so that they can complement and support each other for the purpose of developing and implementing data-driven technologies and solutions in development planning and operational management in order to balance and advance sustainability goals.

Furthermore, bringing about the necessary changes to attain the future vision requires engaging stakeholders in long-term cooperation, which is strongly dependent on the approach to their participation and management. The data-driven smart sustainable city of the future provides an opportunity that brings numerous stakeholders together and pool their substantive knowledge to put forth the relevant long-term plans that promote sustainable development in the era of big data. However, considering the time horizon of 25-50 years reasonably needed to develop the data-driven smart sustainable city as a desired future, coupled with the findings from the six cases investigated, the issue of uncertainty remains problematic. For example, it is unfeasible to make accurate, comprehensive top-down plans informed by bottom-up inputs from citizens for long-term cooperation. Moreover, as stakeholders usually have differing interests, it is necessary to develop and implement a framework for understanding and aligning their interests in ways to fit in with the newfound objectives of the government of a given city. The newfound objectives are associated with a rather more integrated approach to urban planning and development in regard to balancing and advancing the environmental, economic, and social goals of sustainability on the basis of the IoT and big data technologies. Such approach should be based on the opportunities, capabilities, and constraints of each city. While change has unpredictable consequences, the possibility for most of the stockholders to walk away as future winners is high as long as their alignment dovetails with the agenda of sustainable development and technological development. Moreover, in order to get all stakeholders on board, each city needs a tool to conceptualize long-term developments.

As a multifaceted process, governing the data-driven smart sustainable city of the future highlights how local government and stakeholders decide how to plan, finance, and manage urban areas, and involves a continuous process of negotiation and contestation over the allocation of technological, material, and social resources as well as political will and influence. In short, how different actors are engaged in the planning and steering of the city. While this increases public engagement and strengthen participatory and democratic processes, it can also lead to uncertainty and unpredictability in decision making. Maintaining the process of sustainable urban development towards achieving the goals of urban sustainability in the era of big data is an enormous challenge in terms of planning and management, and requires a collective approach to coordinating actions and decision-making processes, thereby the necessity of advanced forms of city governance and thus the importance of governance networks. Indeed, the kind of transformations associated with the data-driven smart sustainable city of the future calls for more open and inclusive models for city governance. In this regard, the 
city government needs to establish synergy between various actors and should, more importantly, invest in developing a bottom-up innovative ecosystem to engage citizens in a variety of ways. In managing urban transformations, the city government needs to play a strategic role in promoting participatory and democratic processes while forging partnerships with and among key stakeholders. The emerging forms of urban governance structures allow widespread participation of the citizenry by developing technologies that ensure shared knowledge for democratic governance and informed participation (see Bibri 2018 for a detailed analytical account in relation to data-driven smart sustainable cities of the future). However, the relationships among the stakeholders and institutions involved in city governance determine what happens in the city. City governance provides a means of understanding the relational dynamics between urban development and urban actors in the long term-in other words, the way governance networks work to maintain the process of urban development toward achieving the goals of sustainability. Governance networks function through various forms of network governance (whereby network is viewed as a mechanism of coordination) to promote sustainable development. Network coordination in public sector can provide considerable benefits, including enhanced learning, the efficient use of resources, increased capacity to plan for and address complex problems, and better services for citizens (Provan and Kenis 2007). The power and efficiency gains of governance networks derive from their distinctive features, namely:

- horizontal articulations of public, semi-public, and private actors that are dependent on one another's resources and capacities but operationally autonomous;

- these actors carry out negotiations within an institutionalized framework based on an amalgam of normative, cognitive, regulative, and imaginary elements;

- this framework is restricted by external forces as to its self-regulating patterns and actions; and

- its purpose is to contribute to the production of public purpose as an expression of plans, policies, and regulatory frameworks that are valid for, and directed towards, the general public.

The forms of coordination enabled by governance networks can be an apt response to the question of how to tackle complex policy problems and governance tasks in relation to the planning and development of the data-driven smart sustainable city of the future. This also justifies why governance networks need to be formed and why they can contribute to efficient governance within the field of policy and planning when it comes to sustainability transitions. However, governance networks are likely to fail on various counts due to otherwise inefficient coordination. Careful network governance is essential as it might prevent major dislocations and mitigate the impact of various disturbances; however, optimizing the functioning of governance networks on all dimensions is a daunting task (Klijn and Koppenjan 2004) and poses special conundrums.

Profoundly political, city governance is shaped and influenced by the creation and operation of political institutions and their mechanisms, government capacity to make and implement decisions and the extent to which these decisions secure and uphold environmentally sound, economically viable, and socially beneficial development through the synergistic integration of the more established strategies of sustainable 
cities and the more innovative solutions of data-driven smart cities towards achieving the long-term goals of sustainability. This envisioned outcome implies that the datadriven smart sustainable city of the future needs solid and effective policies that allow and regulate investments, partnerships, and developments of the kinds that contribute to and sustain its progress towards the sought goal. Here urban policies reflect fundamental social agreements about how the data-driven smart sustainable city of the future will continue to be built and transformed and how their inhabitants will relate to each other. Among the common mechanisms of political instilutions used in the operation that link the data-driven smart sustainable city of the future to political action are: creating regulatory and policy instruments and carrying out legislations; assigning scholarly roles and non-governmental institutional positions to particular universities and organisations (in terms of R\&D activities, technology and innovation, policy recommendation, vision construction, and so on); orienting investments, supposing projects, providing incentives, advocating product and service adoption, organizing forums and symposiums, encouraging local and national programs, and creating comprehensive or master plans. Political institutions create, enforce, and apply or enact laws, and often mediate conflict and make policy on different societal systems. In this context, however, political processes represent the set-up under which dynamic networks of urban actors can interact within diverse urban sectors in the development, diffusion, and utilization of knowledge and technology pertaining to the data-driven smart sustainable city of the future.

The role of policy is associated with aligning and mobilizing different urban actors in the same direction in regard to the future vision. Worth pointing out is that the interactions between policy actors and the ability of policymaking mechanisms are affected by institutions as a set of factors (actions, rules, social structures, and practices) as to the adoption and implementation of effective responses to the various problems of policy in relation to sustainability and technology. Emergency problem is the first stage of the policy process, in addition to agenda setting, consideration of policy options, decision-making, implementation, and (6) evaluation (Jordan and Adelle 2012). Generally, institutions facilitate the coordination between a range of actors and networks, mediating the regulations and rules that govern those behaviors that are deemed of importance for society to make progress towards sustainability. Public policy consists of the set of actions-plans, laws, regulations, and behaviors-adopted by a city government. City governance draws attention to the extent to which these actions are often performed by city agents rather than directly by a city government, and also includes the relationships among the many players (stakeholders) involved and the goals of the city.

\section{Discussion}

Based on the four case studies conducted on the prevailing paradigms of sustainable urbanism and the emerging paradigms of smart urbanism, numerous benefits of the ecocity and the compact city have been realized and many potentials and opportunities of the data-driven smart city and the environmentally data-driven smart sustainable city are being unlocked and exploited. The purpose of their identification and enumeration is to highlight the added value of their combination within the framework of the data-driven smart sustainable city of the future in regard to boosting the benefits of 
environmental, economic, and social sustainability by means of integrating the design strategies and solutions of sustainable cities and smart cities.

Up till now, the four models of urbanism and investigated are regarded as weakly connected as approaches and more or less fragmented as landscapes at the technical and policy levels. The compact city and eco-city models, which have been around for over four decades or so, have many overlaps among them in their ideas, concepts, and visions, as well as distinctive concepts and key differences in terms of planning practices and design strategies. The overlap is justified by the fact that they both represent the central models of sustainable urbanism. As to the data-driven smart city, as an emerging paradigm of smart urbanism, it shares the challenges of sustainable development with the eco-city and compact city models, with the main difference being that it focuses more on the use and application of the IoT and big data technologies to overcome these challenges-than on the planning practices and design strategies of urban sustainability. Concerning the environmentally data-driven smart sustianable city model, it emphasizes the environmental dimension of sustainability and employs datadriven solutions to reach environmental targets. In this sense, it combines concepts and ideas from both the eco-city and the data-driven smart city. These models are increasingly being merged together on the basis of the IoT and big data analytics in a bid to confront the significant challenges posed by climate change in the face of urbanization. However, while they both implement data-driven solutions to improve and advance environmental sustainability, they remain significantly divergent with respect to their visions, policies, strategies, and priorities, thereby the meaningfulness and relevance of integrating their sustainable and technological solutions into one model.

While the environmental goals of sustainability tend to dominate in the discourse of the eco-city (e.g., Mostafavi and Doherty 2010; Holmstedt et al. 2017), the discourse of the compact city emphasizes the economic goals of sustainability (e.g., Bibri et al. 2020; Hofstad 2012; Jenks and Jones 2010), with the social goals of sustainability being of less focus in the eco-city than in the compact city (e.g., Bibri 2020; Lim and Kain 2016; Heinonen and Junnila 2011; Bramley and Power 2009; Rapoport and Vernay 2011). In view of that, it is of high relevance and importance to integrate the compact city and ecocity models so as to consolidate and harness their design strategies and sustainable technology solutions to deliver the best outcomes of sustainability. Their integration is indeed justified by the fact that the compact city needs to improve its environmental performance, that the eco-city needs to improve its social performance, and that both contribute differently to economic sustainability, with the former focusing on mixedland use strategy and the latter on green-tech innovation strategy. Another argument supporting their integration is that they are compatible and not mutually exclusive. Some of the attempts undertaken to integrate these models tend to provide ideal approaches, to simply combine some ideas from each one of them to form new loosely integrated models, or to strengthen one model through adding principles from the other, all with the objective to incorporate the lacking or missing aspects of sustainability (e.g., Farr 2008; Harvey 2011; Jabareen 2006; Kenworthy 2019; Marcotullio 2017; Roseland 1997; Suzuki et al. 2010). However, as this work is more often than not based on design with respect to architecture and planning discipline, it emphasizes more on creativity, common sense, ideal target pursuit, and future scenarios, rather than fact-based 
evidence explanation, empirically grounded research, or scientific finding-oriented exploration.

The conscious push for sustainable cities to become smarter and thus more sustainable in the era of big data is due to the problematicity surrounding their development planning approaches and operational management mechanisms, as well as the fragmentation of their designs and techmologies related to compact cities and eco-cities as the most advocated models of sustainable urban form. This has a clear bearing on their performance with respect to the contribution to and balancing of the goals of sustainability. Indeed, over the last two decades, research within the field of sustainable urban forms, especially compact cities and eco-cities, has produced conflicting, uncertain, weak, and non-conclusive results (e.g., Bibri 2020b, c; Cugurullo 2016; Jenks and Dempsey 2005; Kaido 2005; Kärrholm 2011; Lim and Kain 2016; Neuman 2005; Williams 2010) concerning the actual benefits and effects these forms of human settlements claim to deliver. In this light, it has been argued that the dificiencies, shortcomings, struggles, and bottlenecks associated with sustainable cities are largely due to how they have long been studied, understood, planned, designed, and managed. This pertains to data scarcity, research methods with inherent limits and biases, longterm and static planning approaches, simulation models unable to deal with complex systems in terms of their design, and inefficient operational management mechanisms. This situation is dramatically changing thanks to the multifaceted potential of the IoT and big data analytics as the prerequisite enabling technologies of smart cities, nevertheless.

The technological strand of this study has been addressed in more detail in the two case studies conducted on the emerging paradigms of smart urbanism. One of the key aspects to highlight in regard to this strand is the role of smart cities in connecting the aforementioned infrastructures associated with the transformations needed to attain the future vision through the identified strategies and pathways. This connection is a way to leverage the collective intelligence of the data-driven smart sustainable city of the future through the synergic and substantive effects of advanced ICT with regard to increasing the benefits of sustainability. In other words, in making sustainable cities cleaner, safer, more resilient, and more efficient through urban computing and intelligence supporting joined-up and short term planning approaches. This can be accomplished by harnessing the vast troves of data that can be generated from across many urban domains thanks to advanced computational analytics techniques as well as urban operation systems and analytical centers (e.g., Ameer and Shah 2018, Batty et al. 2012; Bibri 2019a; Kitchin 2014, 2016; Nikitin et al. 2016, Rathore et al. 2016). Sustainable cities involve the kind of challenges that are enormous enough to call for a datadriven approach to planning as a function of many diverse city stakeholders. Joined-up planning is a form of integration and coordination that enables the city-wide effects associated with environmental, economic, and social sustainability to be monitored, understood, and embedded into the designs and responses of sustainable cities in terms of their operational functioning, I.e., forms, structures, spacial organisations, activities, and services as embedded in space and time.

However, sustainable cities are so characterized by their specificities as regards their compact and ecological dimensions and how and the extent to which these are integrated in a given city area or district. This in turn shapes the way in which the IoT and 
big data technologies can be embedded in the fabrics of sustainable cities, as well as how they can be applied in their operational management processes and development planning practices. In more detail, sustainable cities essentially exhibit key differences in the way they prioritize and implement their strategies and solutions, depending on many intertwined factors, notably physical, geographical, socio-political, economic, environmental, and historical. In particular, the IoT and big data technologies might work in one sustainable city in a way that is different in another. Hence, they should sometimes be dramatically reworked to be applicable in the context where they are embedded. Besides, sustainable cities do not have a unified agenda as a form of strategic planning, and data-driven decisions are unique to each sustainable city, so are environmental, economic, and social challenges. Big data are the answer, but each sustainable city sets its own questions based on what characterize it in regard to visions, policies, strategies, pathways, goals, and priorities. Regardless, it is important for sustainable cities to make the best use of their local opportunities and capabilities as well as to assess their potentials and constraints from a more integrated perspective when it comes to the operational management and development planning related to their compact, ecological, and technological landscapes and approaches.

Furthermore, the key institutional transformations needed to support the balancing of the three dimensions of sustainability and to enable the introduction of data-driven technologies and the adoption of applied data-driven solutions in city operational management and development planning were identified and enumerated with the objective to highlight the kind of changes that are required to develop and implement a functional model for data-driven smart sustainable cities of the future. A global trend at play today is the decentralization of the city management, where local authorities are becoming more and more empowered and resourceful to address and overcome the challenges of sustainability, whether in relation to sustainable cities or smart cities. In turn, in order for civic institutions to assume their increasing responsibility, they need to implement more effective frameworks for city development planning. Civic institutions are associated with some of the key issues that the data-driven smart sustainable city of the future should think about in improving the quality of urban environments, which include:

- Forming partnerships with civic institutions to use resources more efficiently and control them more safely, to promote more sustainable land use, and to preserve the biodiversity of natural ecosystems and reduce pressure on their services, with the ultimate aim to improve economic and societal outcomes. The latter involves achieving beneficial community effects, enhanced communication and interaction, and improved social well-being while boosting local economies and maximizing existing resources.

- Looking for short-term activities and temporary uses for institutions to meet the diverse needs of communities while capital funding is scarce. These new partnerships and ways of thinking about public resources provide a holistic and creative new approach to sustainability. They develop flexible urban places that may be used for a variety of functions to improve the quality of life for years to come. 
- Promoting and engaging in cooperative planning around shared resources among diverse institutions.

- Working with local residents and stakeholders to come up with ideas to maximize the utilization of education and cultural facilities (universities, schools, municipal offices, etc).

Sustainable cities can use what smart cities have to offer in this regard to enhance their practices. This involves strengthening existing institutionalized practices and competences for supporting the balancing of the three dimensions of sustainability, as well as for developing and establishing new city management and development practices and competences in response to the latest innovations in data-driven technologies. These are increasingly becoming the main driving force of sustainable development in the era of urbanization. Data-driven technological innovations are nurturing or fostering "sociotechnical configurations, which grow and displace incumbent regime activities" (Berkhout et al. 2003), as well as providing lessons and insights to policymakers to manage sustainability transitions. It remains to be seen if these transformative changes will be realized, which depends on the extent to which data-driven technological innovations will solve the challenges of sustainable urbanism and provide concrete value of sustainability. While data-driven technologies are bringing about massive changes to how sustainable cities can function by enabling them to monitor, analyze, model, and simulate their systems for better outcomes, the question is to what extent these developments will continue to be used meaningfully and to the collective advantage of citizens. Any potential disadvantages is yet to be seen as new advancements in artificial intelligence and the IoT will emerge together with new directions of their use. This is predicated on the assumption that all technological developments come with their dark side. Indeed, while big-data analytics and artificial intelligence can bring numerous advantages to urban sustainability, it is important to acknowledge the fact that these advanced technologies can be problematic, and therefore, policy-makers and planners should be careful when employing them. Many recent studies have discussed the potential urban problems and issues triggered by big-data analytics and artificial intelligence in the context of smart sustainable urbanism (e.g., Cugurullo 2020; Yigitcanlar and Cugurullo 2020).

\section{Conclusion}

Data-driven smart sustainable cities hold great potential to instigate major transformative changes on multiple scales by synergistically linking the agendas of urban development, sustainable development, and technological development to add a whole new dimension to sustainability. This analytical work presents a compilation of real-world experiences, successful practices, and positive outcomes in relation to sustainable urbanism and smart urbanism. The collection of the four case studies is intended to allow the reader to have a broad view on the types of technologies and solutions that could enhance and consolidate the design strategies and technology solutions of sustainable cities in ways that increase their contribution to the goals of sustainability.

This paper identified, distilled, and enumerated the key benefits, potentials, and opportunities of sustainable cities and smart cities with respect to the three dimensions of 
sustainability. Sustainable cities are always about citizens. Being data-driven smart about sustainable cities requires to connect directly to the concerns and needs of people concerning environmental protection, economic regeneration, and social equity. Historically, people have always moved to and preferred to live in sustainable cities to improve the quality of their lives, and smart urbanism is embraced anew as a strategic move to create sustainable cities that make urban living more sustainable over the long run-in short, that last. Towards this end, sustainable cities have to learn faster and identify strategic pathways to achieve synergistic and balanced effects of sustainability through integrating their design strategies and technology solutions with the emerging data-driven technolgies and solutions of smart cities. These effects involve the benefits that should be increased, the potentials that should be exploited, and the opportunities that should be explored in the ambit of the data-driven smart sustainable city of the future. Indeed, this emerging paradigm of urbanism is generating worldwide attention as a powerful framework for strategic sustainable urban development, thereby gaining momentum as an academic discourse and thus settling into institutional structures and new practices and competences.

This paper also identified, distilled, and enumerated the key institutional transformations needed to support the balancing of the dimensions of sustainability and to enable the introduction of data-driven technology and the adoption of applied data-driven solutions in city operational management and development planning. The identified institutional practices and competences are framed within the datadriven smart sustainable city of the future. Therefore, they are intended to reinforce and complement each other in the endeavor to balance and advance the goals of sustainbility. This requires developing and implementing an institutional framework, the systems of formal laws, regulations, and procedures as well as stakeholders with their roles and informal conventions and norms, that shape socioeconomic activities and behaviors. This framework is a prerequisite for the successful implementation of advanced city operational management and development planning intervention projects and initiatives for enabling the functioning of the datadriven smart sustainable city of the future. The essence of this new integrated model lies in providing the needed tools, techniques, methods, systems, platforms, and infrastructures enabled by the core enabling and driving technologies of the IoT and big data analytics for sustainable cities to have a more measurable, targeted, and hormonized contribution to sustainability. This in turn means finding and applying more effective ways of translating sustainability into the physical, spatial, environmental, economic, and social forms of the city.

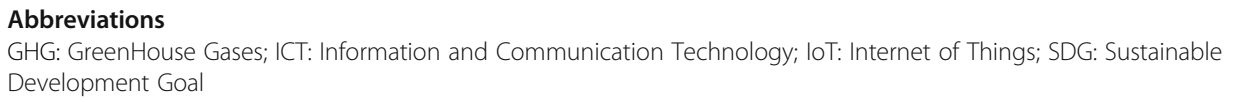


Availability of data and materials

Not applicable.

\section{Competing interests}

The author declared no potential conflicts of interest with respect to the research, authorship, and/or publication of this article.

Received: 13 November 2020 Accepted: 12 February 2021

Published online: 05 March 2021

\section{References}

Ahvenniemi H, Huovila A, Pinto-Seppä I, Airaksinen M (2017) What are the differences between sustainable and smart cities? Cities 60:234-245

Akerman J (2005) Sustainable air transport - on track in 2050. Transp Res D10(2):111-126

Akerman J, Höjer M (2006) How much transport can the climate stand?-Sweden on a sustainable path in 2050. Energy Policy 34(14):1944-1957

Ameer S, Shah MA (2018) "Exploiting Big Data Analytics for Smart Urban Planning," IEEE 88th Vehicular Technology Conference (VTC-Fall), Chicago, IL, USA, 2018, pp. 1-5. https://doi.org/10.1109/NTCFall.2018.8691036

Angelidou M, Psaltoglou A, Komninos N, Kakderi C, Tsarchopoulos P, Panori A (2017) Enhancing sustainable urban development through smart city applications. J Sci Technol Policy Manag 9(2):146-169

Batty M, Axhausen KW, Giannotti F, Pozdnoukhov A, Bazzani A, Wachowicz M et al (2012) Smart cities of the future. Eur Phys 214:481-518

Bengston DN, Westphal LM, Dockry MJ (2020) Back from the future: the Backcasting wheel for mapping a pathway to a preferred future. World Fut Rev 12(3):270-278

Berkhout F, Smith A, Stirling A (2003) 'Socio - technological regimes and transition contexts', SPRU Electronic Working Paper Series 106

Bettencourt LMA (2014) The uses of big data in cities. Santa Fe Institute, Santa Fe

Bibri SE (2018) Managing urban complexity: project and risk management and polycentric and participatory governance. In: Smart sustainable cities of the future, The urban book series. Springer, Cham. https://doi.org/10.1007/978-3-319-73981-6_8

Bibri SE (2019a) On the sustainability of smart and smarter cities in the era of big data: an interdisciplinary and transdisciplinary literature review. J Big Data 6(25):2-64

Bibri SE (2019b) The anatomy of the data-driven smart sustainable city: instrumentation, datafication, computerization and related applications. J Big Data 6:59

Bibri SE (2019c) The sciences underlying smart sustainable urbanism: unprecedented paradigmatic and scholarly shifts in light of big data science and analytics. Smart Cities 2(2):179-213

Bibri SE (2020a) Advances in the leading paradigms of urbanism and their amalgamation: compact cities, eco-cities, and data-driven smart cities, vol 2020. Springer Nature Switzerland AG, Cham

Bibri SE (2020b) The eco-city and its core environmental dimension of sustainability: green energy technologies and their integration with data-driven smart solutions. Energy Inform 3(4). https://doi.org/10.1186/s42162-020-00107-7

Bibri SE (2020c) Compact urbanism and the synergic potential of its integration with data-driven smart urbanism : an extensive interdisciplinary literature review. J Land Use Policy 97:1-20

Bibri SE (2020d) A methodological framework for futures studies: integrating normative backcasting approaches and descriptive case study design for strategic data-driven smart sustainable city planning. Energy Inform 3:31. https://doi. org/10.1186/s42162-020-00133-5

Bibri SE, Krogstie J (2016) On the social shaping dimensions of smart sustainable cities: a study in science, technology, and society. Sustain Cities Soc 29:219-246

Bibri SE, Krogstie J (2017) ICT of the new wave of computing for sustainable urban forms: their big data and context-aware augmented typologies and design concepts. Sustain Cities Soc 32:449-474

Bibri SE, Krogstie J (2020a) Smart eco-city strategies and solutions for sustainability: the cases of royal seaport, Stockholm, Western Harbor, Malmö, Sweden. Urban Sci 4(1):1-42

Bibri SE, Krogstie J (2020b) The emerging data-driven Smart City and its innovative applied solutions for sustainability: the cases of London and Barcelona. Energy Inform 3:5. https://doi.org/10.1186/s42162-020-00108-6

Bibri SE, Krogstie J (2020c) Environmentally data-driven smart sustainable cities: applied innovative solutions for energy efficiency, pollution reduction, and urban metabolism. Energy Inf 3(1):1-59 In Press

Bibri SE, Krogstie J (2020d) Data-driven smart sustainable cities: a novel model of urbanism and its Core dimensions, strategies, and solutions. J Fut Stud 25(2):77-94 In Press

Bibri SE, Krogstie J (2021) A Novel Model for Data-Driven Smart Sustainable Cities of the Future: a Strategic Roadmap to Transformational Change in the Era of Big Data. Future Cities and Environment 7(1):3. https://doi. org/10.5334/fce.116

Bibri SE, Krogstie J, Kärrholm M (2020) Compact city planning and development: emerging practices and strategies for achieving the goals of sustainability. Dev Built Environ 4:1-2

Bifulco F, Tregua M, Amitrano CC, D'Auria A (2016) ICT and sustainability in smart cities management. International Journal of Public Sector Management 29(2):132-147

Bramley G, Power S (2009) Urban form and social sustainability: The role of density and housing type. Environment and Planning B: Planning and Design 36(1):30-48

Burton E (2002) Measuring urban compactness in UK towns and cities. Environment and Planning B: Planning and Design 29 $219-250$

Cugurullo F (2016) Exposing smart cities and eco-cities: Frankenstein urbanism and the sustainability challenges of the experimental city. Environ Plan A Econ Space 50:73-92

Cugurullo F (2020) Urban artificial intelligence: from automation to autonomy in the Smart City. Front Sustain Cities 2:38. https://doi.org/10.3389/frsc.2020.00038 
Dempsey N (2010) Revisiting the compact city? Built Environ 36(1):5-8

Eden Strategy Institute. (2018). Report, https://www.smartcitygovt.com

Farr D (2008) Sustainable urbanism. Wiley

Harvey F (2011) Green vision: The search for the ideal eco-city. Financ Times, London

Hashem IAT, Chang V, Anuar NB, Adewole K, Yaqoob I, Gani A et al (2016) The role of big data in smart city. Int J Inf Manag 36:748-758

Heinonen J, Junnila S (2011) Implications of urban structure on carbon consumption in metropolitan areas. Environmental Research Letters 6(1):014018

Hofstad H (2012) Compact city development: high ideals and emerging practices. Eu J Spatial Plann:1-23

Höjer M, Gullberg A, Pettersson R (2011) Backcasting images of the future city-time and space for sustainable development in Stockholm. Technol Forecast Soc Chang 78(5):819-834

Holmberg J (1998) Backcasting: a natural step in operationalizing sustainable development. Greener Manag Int 23:30-51

Holmstedt L, Nilsson A, Mäkivierikko A, Brandt N (2017) Stockholm Royal Seaport moving towards the goals—Potential and limitations of dynamic and high resolution evaluation data, Energy and Buildings 169:388-396

Jabareen YR (2006) Sustainable urban forms: their typologies, models, and concepts. J Plann Educ Res 26:38-52

Jenks M, Dempsey N (eds) (2005) Future forms and design for sustainable cities. Architectural Press, Oxford

Jenks M, Jones C (eds) (2010) Dimensions of the sustainable city (Vol. 2). Springer, London

Jordan AJ, Adelle C (eds) (2012) Environmental policy in the European Union 3rd edition. Routledge, London

Joss S (2010) Eco-cities-A global survey 2009. WIT Transactions on Ecology and the Environment, 129:239-250.

Joss S, Cowley R, Tomozeiu D (2013) Towards the ubiquitous eco-city: an analysis of the internationalisation of eco-city policy and practice. J Urban Res Pract 76:16-22

Kaido K (2005) Urban densities, quality of life and local facility accessibility in principal Japanese cities. In: Jencks M, Dempsey N (Eds) Future Forms and Design for Sustainable Cities, pp. 311-338. Architectural Press, Oxford

Kärrholm M (2011) The scaling of sustainable urban form: Some scale—Related problems in the context of a Swedish urban landscape. European Planning Studies 19(1):97-112

Kenworthy JR (2006) The eco-city: Ten key transport and planning dimensions for sustainable city development. Environment and Urbanization 18(1):67-85.

Kenworthy JR (2019) Urban transport and eco-urbanism: a global comparative study of cities with a special focus on five larger Swedish urban regions MDPI: Urban Science

Kitchin R (2014) The real-time city? Big data and smart urbanism. Geo J 79:1-14

Kitchin R (2016) The ethics of smart cities and urban science. Phil Trans R Soc A 374:20160115

Klijn EH, Koppenjan JFM (2004) Managing uncertainties in networks. Routledge, London

Kumar A, Prakash A (2016) The role of big data and analytics in smart cities. Int J Sci Res 6(14):12-23

Lim HK, Kain J-H (2016) Compact cities are complex, intense and diverse but: can we design such emergent urban properties? Urban Plan 1(1):95

Marcotullio PJ (2017) Towards sustainable cities: east Asian, north American and European perspectives on managing urban regions. Routledge, New York

Miola A (2008) Backcasting approach for sustainable mobility. European Commission, Joint Research Center, Institute for Environment and Sustainability

Mostafavi M, Doherty G (2010) Ecological urbanism. Lars Muller, Switzerland

Murmann JP (2003) Knowledge and competitive advantage: The coevolution of firms, technology and national institutions. Cambridge University Press, Cambridge

Neuman M (2005) The compact city fallacy. J Plan Educ Res 25:11-26

Nikitin K, Lantsev N, Nugaev A, Yakovleva A (2016) Data-driven cities: from concept to applied solutions. PricewaterhouseCoopers (PwC) http://docplayer.net/50140321-From-concept-to-applied-solutions-data-driven-cities.html

Noori N, Hoppe T, de Jong M (2020) Classifying pathways for Smart City development: comparing design, governance and implementation in Amsterdam, Barcelona, Dubai, and Abu Dhabi. Sustainability 12:4030

OECD (2012) Compact city policies: a comparative assessment, OECD'. In: OECD green growth studies, pp 123-158. https:// doi.org/10.1787/9789264167865-en

Pasichnyi O, Levihn F, Shahrokni H, Wallin J, Kordas O (2019) Data- driven strategic planning of building energy retrofitting: the case of Stockholm. J Clean Prod 233:546-560

Perera C, Qin Y, Estrella JC, Reiff-Marganiec S, Vasilakos AV (2017) Fog computing for sustainable smart cities: a survey. ACM Comput Surv 50:3

Prell C, Hubacek K, Reed M (2009) Stakeholder analysis and social network analysis in natural resource management. Soc Nat Resour 22(6):501-518

Provan KG, Kenis P (2007) Modes of network governance: structure, management and effectiveness. J Public Adm Res Theory 18:229-252

Quist J, Knot M, Young W, Green K, Vergragt P (2001) Strategies towards sustainable households using stakeholder workshops and scenarios. Int J Sustain Dev 4:75-89

Quist J (2007) Backcasting for a sustainable future: the impact after 10 years, Ph.D. thesis, Faculty of Technology, policy and management, Delft University of Technology, Delft

Rapoport E, Vernay AL (2011) Defining the eco-city: a discursive approach. In: Paper presented at the management and innovation for a sustainable built environment conference, international eco-cities initiative. The Netherlands, Amsterdam, pp 1-15

Rathore MM, Awais A, Anand P, Seungmin R (2016) Urban planning and building smart cities based on the Internet of Things using Big Data analytics, Computer Networks 101:63-80

Reed MS, Graves A, Dandy N, Posthumus H, Hubacek K, Morris J, Stringer LC (2009) Who's in and why? A typology of stakeholder analysis methods for natural resource management. Journal of Environmental Management 90: 1933-1949

Robinson J (1990) Futures under glass: a recipe for people who hate to predict. Futures 22(8):820-842

Roseland M (1997) Dimensions of the eco-city. Cities 14(4):197-202 
Shahrokni H, Årman L, Lazarevic D, Nilsson A, Brandt N (2015a) Implementing smart urban metabolism in the Stockholm Royal Seaport: smart city SRS. J Ind Ecol 19(5):917-929

Shahrokni H, Lazarevic D, Brandt N (2015b) Smart urban metabolism: towards a real-time understanding of the energy and material flows of a city and its citizens. J Urban Technol 22(1):65-86

Shahrokni H, Levihn F, Brandt N (2014a) Big meter data analysis of the energy efficiency potential in Stockholm's building stock. Energ Buildings 78:153-164

Shahrokni H, van der Heijde B, Lazarevic D, Brandt N (2014b) Big data GIS analytics towards efficient waste management in Stockholm. In: ICT4S-ICT for sustainability. Alantis Press, Stockholm

Sinaeepourfard AJ, Garcia XM-B, Marín-Tordera E, Cirera J, Grau G, Casaus F (2016) Estimating Smart City sensors data generation current and future data in the City of Barcelona. In: Proceedings of conference: the 15th IFIP annual Mediterranean ad hoc networking workshop

Smith N (2003) Remaking scale: Competition and cooperation in pre-national and post-national Europe. In: Brenner N, et al. (eds) State/Space (pp. 227-238). Basil Blackwell, Oxford

Sun Y, Du Y (2017) Big data and sustainable cities: applications of new and emerging forms of geospatial data in urban studies. Open Geospatial Data, Softw Stand 2:24. https://doi.org/10.1186/s40965-017-0037-0

Suzuki $\mathrm{H}$ et al (2010) Eco2 cities ecological cities as economic cities. The World Bank

Thakuriah P, V, Tilahun N, Zellner M (2017) Seeing cities through big data research. In: Methods and applications in urban informatics. Springer International Publishing

Thornbush M, Golubchikov O (2019) Sustainable urbanism in digital transitions: from low carbon to smart sustainable cities. Springer, Berlin. https://doi.org/10.1007/978-3-030-25947-1

United Nations (2015a) Transforming our world: the 2030 agenda for sustainable development, New York Available at: https://sustainabledevelopment.un.org/post2015/transformingourworld

United Nations (2015b) Habitat III issue papers, 21—smart cities (V2.0), New York Available at: https://collaboration.worldbank. org/docs/DOC-20778. Accessed 2 May 2017

United Nations (2015c) Big data and the 2030 agenda for sustainable development Prepared by A. Maaroof. Available at: www.unescap.org/events/call-participants-big-data-and-2030-agendasustainable-development-achievingdevelopment

Vergragt PJ, Quist J (2011) Backcasting for sustainability: Introduction to the special issue 1, Technological Forecasting and Social Change 78(5):747-755

Wangel J (2011) Exploring social structures and agency in backcasting studies for sustainable development. Technol Forecast Soc Change 78(5):872-882

Williams K (2010) Sustainable cities: Research and practice challenges. International Journal of Urban Sustainable Development 1(1):128-132

World Commission on Environment and Development (WCED) (1987) Our common future (the Brundtland report). Oxford University Press, Oxford/New York

Yin RK (2014) Case study research: Design and methods. Sage, Los Angeles

Yin RK (2017) Case study research and applications: design and methods (6th ed.). SAGE Publications, Inc

Yigitcanlar T, Cugurullo F (2020) The sustainability of artificial intelligence: an Urbanistic viewpoint from the lens of smart and sustainable cities. Sustainability 12:8548

\section{Publisher's Note}

Springer Nature remains neutral with regard to jurisdictional claims in published maps and institutional affiliations.

\section{Submit your manuscript to a SpringerOpen ${ }^{\circ}$ journal and benefit from:}

- Convenient online submission

- Rigorous peer review

- Open access: articles freely available online

- High visibility within the field

- Retaining the copyright to your article

Submit your next manuscript at $\boldsymbol{\nabla}$ springeropen.com 